OPEN ACCESS

Edited by:

Tamilselvan Mohan,

Graz University of Technology, Austria

Reviewed by:

Deepansh Sharma,

Amity University Jaipur, India

Meghana Ramani,

Wayne State University, United States

*Correspondence:

Ruchi Agrawal

dr.ruchiagrawal010@gmail.com

${ }^{\dagger}$ These authors have contributed equally to this work

Specialty section: This article was submitted to Nanomaterials,

a section of the journal

Frontiers in Nanotechnology

Received: 26 July 2021 Accepted: 25 October 2021 Published: 15 November 2021

Citation:

Kaur $P$, Sharma $N$, Munagala $M$, Rajkhowa $R$, Aallardyce B, Shastri $Y$ and Agrawal R (2021) Nanocellulose:

Resources, Physio-Chemical Properties, Current Uses and

Future Applications.

Front. Nanotechnol. 3:747329.

doi: 10.3389/fnano.2021.747329

\section{Nanocellulose: Resources, Physio-Chemical Properties, Current Uses and Future Applications}

\author{
Prabhpreet Kaur ${ }^{1+}$, Neha Sharma ${ }^{1 \dagger}$, Meghana Munagala ${ }^{2}$, Rangam Rajkhowa ${ }^{3}$, \\ Ben Aallardyce ${ }^{3}$, Yogendra Shastri ${ }^{2}$ and Ruchi Agrawal ${ }^{1 *}$
}

${ }^{1}$ TERI-Deakin Nanobiotechnology Centre, The Energy and Resources Institute, TERI Gram, Gurugram, India, ${ }^{2}$ Department of Chemical Engineering, Indian Institute of Technology Bombay, Mumbai, India, ${ }^{3}$ Institute for Frontier Materials, Deakin University, Victoria, VIC, Australia

The growing environmental concerns due to the excessive use of non-renewable petroleum based products have raised interest for the sustainable synthesis of biobased value added products and chemicals. Recently, nanocellulose has attracted wide attention because of its unique properties such as high surface area, tunable surface chemistry, excellent mechanical strength, biodegradability and renewable nature. It serves wide range of applications in paper making, biosensor, hydrogel and aerogel synthesis, water purification, biomedical industry and food industry. Variations in selection of source, processing technique and subsequent chemical modifications influence the size, morphology, and other characteristics of nanocellulose and ultimately their area of application. The current review is focused on extraction/ synthesis of nanocellulose from different sources such as bacteria and lignocellulosic biomass, by using various production techniques ranging from traditional harsh chemicals to green methods. Further, the challenges in nanocellulose production, physio-chemical properties and applications are discussed with future opportunities. Finally, the sustainability of nanocellulose product as well as processes is reviewed by taking a systems view. The impact of chemicals, energy use, and waste generated can often negate the benefit of a bio-based product. These issues are evaluated and future research needs are identified.

Keywords: nanocellulose, cellulose nanocrystals (CNC), cellulose nanofibrils (CNF), life cycle assessment (LCA) analysis, techno-economic assessment (TEA)

\section{INTRODUCTION}

The rising environmental concerns due to the excessive usage of synthetic, non-renewable, recalcitrant petroleum-based materials have driven the research for sustainable, renewable and biodegradable products. Cellulose is one of the most abundant natural polymers with attractive properties such as renewability, potentially low cost, biocompatibility, and biodegradability. It is abundantly available as part of lignocellulosic biomass, such as forest residues, agricultural residues, and energy crops. A great deal of research is focused on cellulose extraction from such sustainable sources and its applications in various eco-friendly products (Satlewal et al., 2018a; Satlewal et al., 2018b).

With the evolution in the field of nanotechnology and the emergence of new and advanced nanomaterials, the traditional research practices and many industrial applications are now getting 
reformed. Nanocellulose has the desirable properties of cellulose such as biodegradability, low density and non-toxicity; along with certain special properties such as great mechanical and thermal stability, self-assembly in aqueous dispersion media, reinforcing capabilities and long-lasting nature (Thomas et al., 2018). It has been applied in various applications such as food packaging, chemical industry as viscosity modifier, biomedicine, mechanical reinforcement of matrices, and membrane filtration (Squinca et al., 2020). With the decrease in size from micrometres such as in cellulose polymer chains to nanometres such as in nanocellulose, various parameters such as effective surface area, crystallinity, and mechanical strength change. These variations can be analysed using different characterization techniques.

As per the Technical Association of the Pulp and Paper Industry (TAPPI), nanocellulose could be broadly categorized into: 1) cellulose nanocrystals (CNCs) and 2) cellulose nanofibrils (CNFs) (Shak et al., 2018). Nanocellulose extraction primarily involves a combination of enzymatic, chemical or mechanical treatments to attain purified cellulose. This cellulose is then subjected to chemical processes typically by acid hydrolysis to separate amorphous domains to obtain CNCs, whereas CNFs are obtained via mechanical treatments (Eapen et al., 2020). A detailed comparison of the properties of CNCs and CNFs isolated from different feedstocks and methods is discussed in literature (Borjesson and Westman, 2015; Shak et al., 2018; Trache et al., 2020) and in the present review.

In this review, various sources and types of nanocellulose with emphasis on different production methods such as pre-treatment, mechanical and chemical methods with recent literature are presented to build an understanding of how the cellulose fibers disintegrate into primary constituents nanocellulose (Agrawal et al., 2021a; Agrawal et al., 2021b). This review also discusses the unique properties of nanocellulose and general awareness for eco-friendly products that have directed both research and industrial attention towards nanocellulose and its applications. Moreover, nanocellulose (both CNCs and CNFs) are presently mostly confined to lab-scale due to scalability issues, high energy demand, time consuming process, and high production costs (Trache et al., 2020). Environmental impacts associated with higher energy demands and chemical usage pose an additional limitation (Arvidsson et al., 2015). Performing life cycle assessment (LCA) and techno-economic assessment (TEA) at early development stages of a production routes could address these challenges. Such assessment studies help in identification of the process improvement opportunities to improve the material and energy efficiency. Even though a few LCA studies are available in public domain, TEA studies for CNCs and particularly CNFs are quite limited (de Assis et al., 2017; de Assis et al., 2017; Bondancia et al., 2020; Blair et al., 2021) This work reviews these existing studies and summarizes the key learning and research gaps.

\section{CELLULOSE STRUCTURE AND COMPOSITION}

Cellulose is the most abundant renewable compound found in the biosphere with an estimated production 1,012 tonnes annually by photosynthesis (Sundarraj and Ranganathan, 2018). It is an unbranched polysaccharide composed of D-glucose units linked via $\beta(1,4)$ glycosidic linkage. Every monomer unit in chain is twisted at $180^{\circ}$ compared to its neighbours. The repeating unit of cellulose is a disaccharide cellobiose (Gardner and Blackwell, 1974). Cellobiose units are linked together to produce long homo polymer cellulose chains. Adjacent cellulose chains are linked by hydrogen bonding and van der Waals forces during biosynthesis promote stacking of the chains into elementary fibrils. Numerous elementary fibrils are further bundled together to produce micro-fibrils, which in turn are bundled to form macro-fibrils or cellulosic fibers. Figure 1 shows the hierarchical structure of cellulose from bundle of cellulose fibers to single microfibril and its microstructure. Native cellulose fibers are composed of both ordered (crystalline) and disordered (amorphous) domains. Its crystallinity can range from 40 to $70 \%$ varying on the basis of the source and the extraction procedure. The amorphous regions are preferably broken down by physical, chemical, physicochemical and enzymatic treatments. The degree of polymerization of native cellulose varies from 1,500 to 3,500 depending on source of cellulose and the treatment used for separation (Hallac and Ragauskas, 2011).

\section{NANOCELLULOSE AND ITS TYPES}

Nanocellulose is defined as the cellulose molecules with at least one dimension in nanoscale $(1-100 \mathrm{~nm})$. Development in the emerging field of nanotechnology has made nanocellulose a more attractive research subject than its cellulose counterpart. The main reason for popularity of nanocellulose is that a uniform material with enhanced physicochemical and mechanical properties and crystallinity can be formed by simply reducing the size of cellulose fiber (Suryanegara et al, 2010). Each elementary units of cellulose is strong; when assembled into a fiber, the defects in the assembly make the fiber weaker and theoretical strength of combination of elements in a fiber is poor. So when nanoelements are extracted they show better inherent properties than parent fiber.

Generally, nanocellulose is extracted from cellulose, which is present in various sources such as hardwood, soft wood, agricultural biomass, bacteria, algae, tunicates etc., (Jonoobi et. al., 2015). The cellulose composition is same in all sources, however the structure might show slight variations. The cellulose extracted from plants species have about $13-22 \mu \mathrm{m}$ diameter, and about 44-65\% crystallinity (Ververis et al., 2004), while the cellulose synthetised by bacteria called bacterial cellulose, are naturally nanoscale fibrils, with a diameter of about $10-100 \mathrm{~nm}$ and with a much higher crystallinity of about 90\% (Gorgieva and Trček, 2019).

Typically, cellulose nanostructured materials refer to three major classes: 1) cellulose nanofibers 2) cellulose nanocrystals/ cellulose whiskers 3) bacterial nanocellulose. Cellulose nanofibrils are nanoscale cellulose with diameter of about $5-60 \mathrm{~nm}$ and length in many microns (Habibi et al., 2010). They are often extracted from wood pulp by TEMPO-mediated oxidation method (Jonasson et al., 2020). The fibrils consist of both 


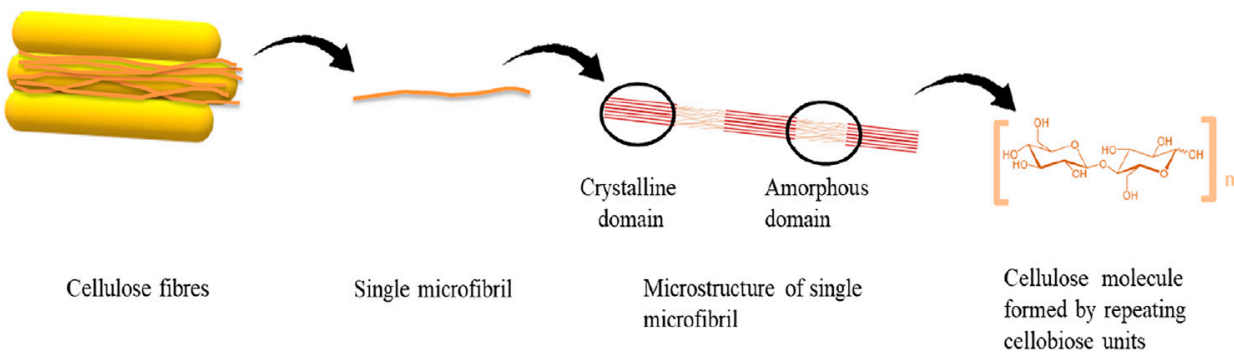

FIGURE 1 | Hierarchical structure of cellulose from bundle of cellulose fibres to single microfibril and its microstructure.

TABLE 1 | Comparison of different types of nanocellulose.

\begin{tabular}{|c|c|c|c|c|}
\hline Properties & Cellulose nanofibers & $\begin{array}{c}\text { Cellulose } \\
\text { nanocrystals }\end{array}$ & Bacterial nanocellulose & References \\
\hline Morphology & Rope like & Needle like & Ribbon like & Trache et al. (2020) \\
\hline Size & $\begin{array}{l}5-60 \mathrm{~nm} \text { diameter and } \\
\text { length in many microns }\end{array}$ & $\begin{array}{l}5 \mathrm{~nm} \text { diameter and } \\
\text { 20-100 nm length }\end{array}$ & $\begin{array}{l}20-100 \mathrm{~nm} \text { diameter and length in } \\
\text { many micrometers }\end{array}$ & $\begin{array}{l}\text { Habibi et al. (2010), Phanthong } \\
\text { et al. (2018), Jonoobi et al. (2015) }\end{array}$ \\
\hline Crystallinity & $59-64 \%$ & $54-88 \%$ & $84-89 \%$ & $\begin{array}{l}\text { Mishra et al. (2018), Gorgieva and } \\
\text { Trček (2019) }\end{array}$ \\
\hline Aspect ratio & $30-300$ & 11 & $\sim 50$ & $\begin{array}{l}\text { Iwamoto et al. (2014), Sofla et al. } \\
(2016)\end{array}$ \\
\hline $\begin{array}{l}\text { Young's modulus in longitudinal } \\
\text { direction (calculated using AFM } \\
\text { technique) }\end{array}$ & $180 \mathrm{GPa}$ & $150 \mathrm{GPa}$ & $78 \mathrm{GPa}$ & $\begin{array}{l}\text { Cao et al. (2011), Guhados et al. } \\
\text { (2005) }\end{array}$ \\
\hline Common sources & Wood, cotton & $\begin{array}{l}\text { Wood, cotton, bacterial } \\
\text { cellulose }\end{array}$ & $\begin{array}{l}\text { Rhizobium, Agrobacterium, } \\
\text { Gluconacetobacter and Sarcina }\end{array}$ & Gupta and Shukla (2020) \\
\hline
\end{tabular}

crystalline and amorphous sections. On the other hand, cellulose nanocrystals are needle shaped and highly crystalline with some residual amorphous regions. The acid hydrolysis method used for obtaining the nanocrystals preferably dissolves the amorphous part, yielding cellulose nanocrystals with $5 \mathrm{~nm}$ diameter and 20-100 nm length (Phanthong et al., 2018). The bacterial nanocellulose is ribbon shaped with about $20-100 \mathrm{~nm}$ size and length in many micrometers (Jonoobi et al., 2015). Bacterial nanocellulose is secreted as an extracellular product during bacterial fermentation by many species of the genera Rhizobium, Agrobacterium, Gluconacetobacter and Sarcina (Gupta and Shukla, 2020). The main advantage of bacterial nanocellulose is that it does not have other unwanted polymers linked to it, unlike cellulose from plant sources. The type of nanocellulose, its size, morphology and other properties depend on the cellulose source, processing conditions during isolation and any pre- or post-treatments. Table 1 shows the comparison of different types of nanocellulose.

\section{PROPERTIES AND CHARACTERIZATION OF NANOCELLULOSE}

Nanocellulose is an interesting material owing to its unique inherent properties like high mechanical strength, thermal stability, high surface area $\left(250 \mathrm{~m} \mathrm{~g}^{-1}\right)$, high aspect ratio, interesting optical and rheological properties and ease of

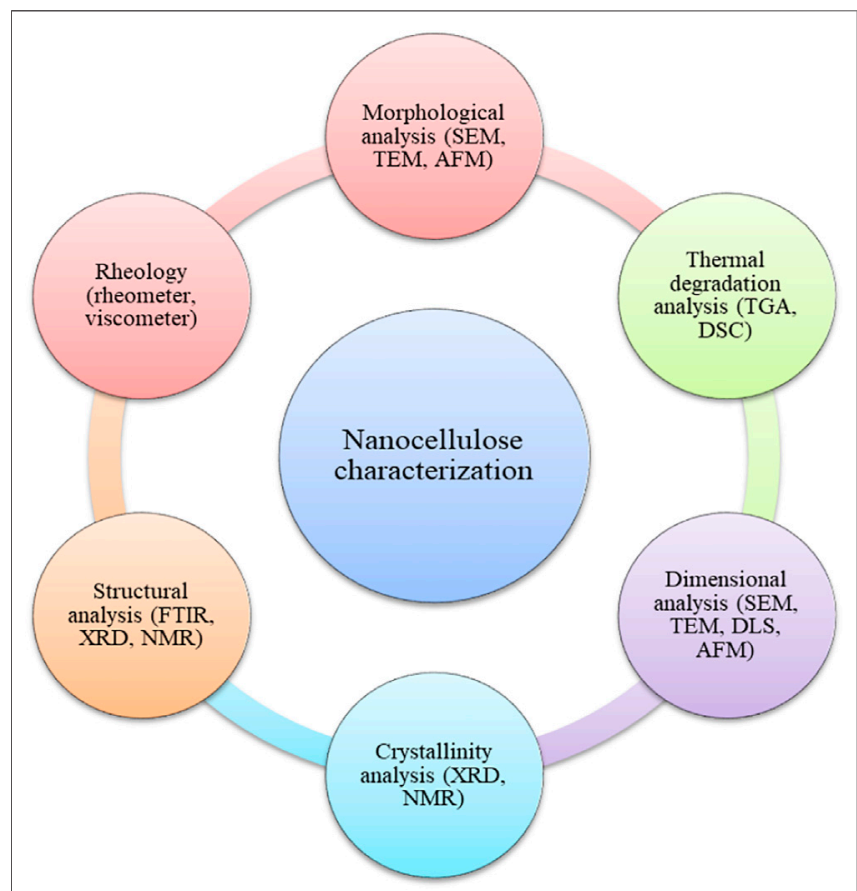

FIGURE 2 | Different techniques for nanocellulose characterization.

surface modification (Barbash et al., 2017; Daud and Lee 2017). Various analytical techniques are used for 
characterization and better understanding of nanocellulose properties as shown in Figure 2.

The surface charge of nanocellulose can be determined by zeta potential value (Yang et al., 2017). The negative values of zeta potential indicate the negatively charged hydroxyl groups $(\rightarrow \mathrm{OH})$ on nanocellulose surface. The dispersion stability can also be determined from the zeta potential values. Usually the absolute value less than $15 \mathrm{mV}$ represents the onset of agglomeration, while the absolute value greater than $30 \mathrm{mV}$ results in a stable nanocellulose suspension (Mohaiyiddin et al., 2016). Yang et al. (2017) showed that nanocellulose derived by TEMPO oxidisation (Zeta potential $=-69 \mathrm{mV}$ ) and acid hydrolysis (Zeta potential $=-34 \mathrm{mV}$ ) formed stable suspension, while high intensity ultra sonication derived nanocellulose (Zeta potential $=-24 \mathrm{mV}$ ) formed agglomeration in suspension.

The hydroxyl groups on the surface of nanocellulose have strong interacting ability and contribute to self-association. This property makes nanocellulose a good reinforcing material in composite matrix of polymers with ten-fold to hundred-fold mechanical strength (Luo et al., 2017), and enhanced optical transparency (Su et al., 2017) as compared to polymer matrix without nanocellulose loading.

Crystallinity index of nanocellulose determines its microstructural and mechanical properties. It is measured using X-ray diffractometer and expressed as crystallinity index (CrI), which is calculated according to Eq. 1 (Segal et al., 1959).

$$
C r I \%=\frac{[I 002-I a m]}{I 002} \times 100 \%
$$

where, I002 is the maximum diffraction intensity (the 002 plane), located around $20=22.5^{\circ}$ and corresponds to the crystalline region; Iam is the minimum diffraction intensity located around $20=18^{\circ}$ and corresponds to the amorphous material.

Microscopic techniques such as Field Emission Scanning Electron Microscopy (FESEM), Transmission Electron Microscopy (TEM) and Atomic Force Microscopy (AFM) can be used for dimensional analysis of nanocellulose. The magnified microscopic images captured using AFM, cryo SEM and TEM showed that all the nanocellulose fibrils and crystals possess right handled chirality at fibril level and at bundle level (Usov et al., 2015). Atomic Force Microscopy (AFM) can be used to probe the topography (Barbash et al., 2019), morphology (Alonso-Lerma et al., 2020), and mechanical properties of nanocellulose. The transverse elastic modulus of wood derived CNCs calculated using AFM was in the range of 18-50 GPa (Lahiji et al., 2010) and that of CNF was $6.9 \pm$ $0.4 \mathrm{GPa}$ (Parvej et al., 2020). It is a favoured technique among researchers due to the attainable resolution and high degree of adaptability. It can be employed to investigate the exact same area of a sample in different environments to see how the local sample changes when exposed to different environments. For instance, the quantitative height difference of cotton cellulose nanofibers in dry and wet state recorded using AFM was used to determine swelling and shrinking, indicated by positive and negative values, respectively (Ottesen and Syverud, 2021).
The hydrodynamic size can be determined by Dynamic Light Scattering (DLS). It gives information about the apparent diameter, and though it is not very accurate for non-spherical particles, it can be used in combination with other techniques to track $\mathrm{CNC}$ consistency and change in size over due time (Marway, 2017). The density and porosity of nanocellulose can be measured using a helium pycnometer. Daicho et al. (2020) reported the density of pure native celluloses, such cotton and tunicin, are approximately $1.60 \mathrm{~g} / \mathrm{cm}^{3}$ using helium pycnometer. In order to study the elemental composition on nanocellulose surface, X-ray photoelectron spectroscopy (XPS) technique could be used (Jordan et al., 2019). In cellulosic materials, four categories of carbon bonds can be identified by XPS: C1 carbons bonded to other carbons or hydrogen $(\mathrm{C}-\mathrm{C}, \mathrm{C}-\mathrm{H})$; $\mathrm{C} 2$ carbons bonded to one oxygen atom $(\mathrm{C}-\mathrm{O})$; $\mathrm{C} 3$ carbons attached to two oxygen atoms or a carbonyl group $(\mathrm{C}=\mathrm{O}$, $\mathrm{O}-\mathrm{C}-\mathrm{O})$ and $\mathrm{C} 4$ carbons from carboxyl groups $(\mathrm{O}-\mathrm{C}=\mathrm{O})$ (Bastidas et al, 2005). Dasong (2015) studied the contribution of each carbon bond in hemp yarn. C1, C2, C3 and C4 were reported $35.76,35.69,18.99,9.56 \%$, respectively; while for the nanocellulose, the contribution of C1, C2, C3 and C4 were $32.66 \%$, 28.67\%, $18.73 \%$, 19.94\%. For nanocellulose, the significant decrease of $\mathrm{C} 2(\mathrm{C}-\mathrm{O})$ and significant increase of $\mathrm{C} 4$ $(\mathrm{O}-\mathrm{C}=\mathrm{O})$ indicated that parts of the hydroxyl groups in cellulose chains were oxidized into carboxyl groups during the oxidation/ sonication process. XPS is also a useful technique to study the various functional groups inserted onto nanocellulose surface during different methods of extraction (Khili et al., 2019; Xu and $\mathrm{Gu}, 2020$ ).

For determining the thermal stability of nanocellulose, various techniques such as thermogravimetric analysis (TGA), differential scanning calorimetry (DSC) and differential thermogravimetry (DTG) can be used (Jordan et al., 2019). TGA of microcrystalline cellulose (MCC) and nanocrystalline cellulose (NCC) obtained from almond and peanut shells, indicated stable materials with a degradation temperature reaching 240 and $200^{\circ} \mathrm{C}$ for MCC and NCC, respectively (Khili et al., 2019). Thermal decomposition temperature for nanocellulose is usually around $200-300^{\circ} \mathrm{C}$, however, thermal stability can be increased by physical or chemical modifications such as desulfation of cellulose nanocrystals extracted by sulphuric acid hydrolysis (Gan et al., 2020).

NMR can be used to evaluate the purity and molecular structure of nanocellulose. Solid state 13C NMR spectroscopy can provide information about the conformation of the constituent carbon atoms of cellulose. In the NMR spectra, the C4 and C6 carbon atoms are distinguishable into crystalline and noncrystalline signals. The signal ratio of $\mathrm{C} 4$ crystalline and noncrystalline phases can be used for calculation of crystallinity index (CI) value of nanocellulose (Daicho et al., 2020). However, nanocellulose tends to agglomerate while drying, therefore solid-state characterization may reflect certain structural changes from drying and not necessarily the precise nature of the individual nanocellulose (Jiang et al., 2014). Therefore, solution-state NMR could be a useful tool for surface characterization of individual nanocellulose in never-dried state. TEMPO oxidation liberates cellulose nanofibrils containing some 


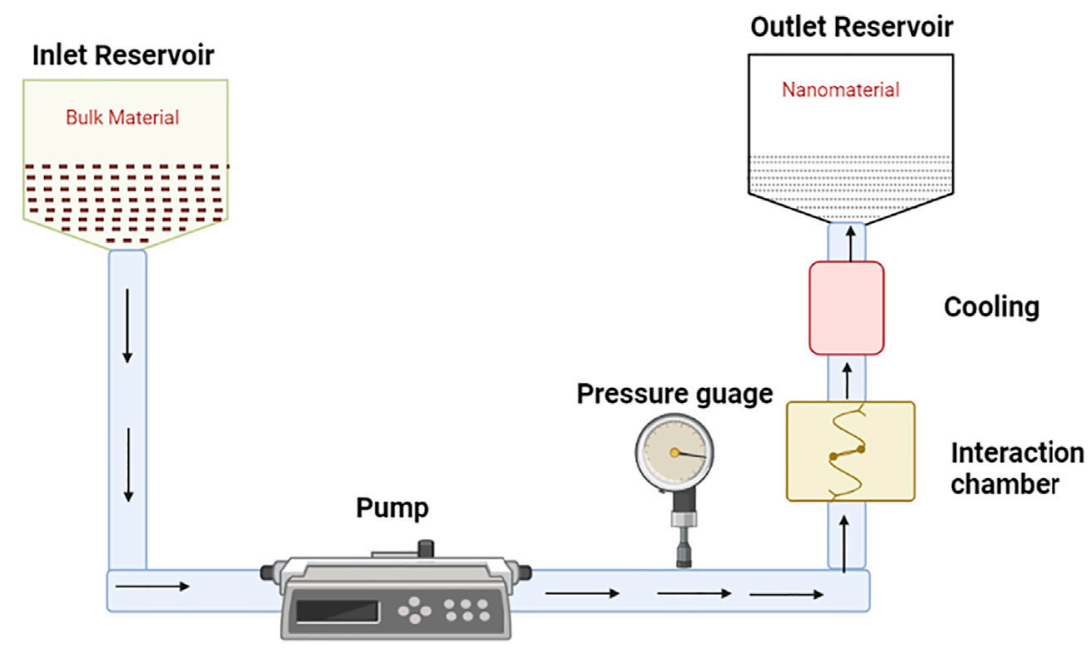

FIGURE 3 | Different hydrolysis methods for the production of cellulose nanofibers.

surface carboxyls converted from C6 primary hydroxyls. These structural modifications were displayed by a weakened signal at C6 $(\delta 60)$ and a new peak at $\delta 175$, in the solution-state $13 \mathrm{C}$ NMR spectra (Jiang et al., 2014). However, almost no C6 and H6 peaks were detected indicating that only the surface nuclei could be detected by NMR of the nanocellulose suspensions (Jiang et al., 2014).

The study of rheological properties of nanocellulose aqueous suspension is important as it can have important consequences on the preparation, processing and combination with other materials for industrial applications. The shape, size and surface composition of nanocellulose mainly affects the rheological properties of nanocellulose (Shafiei-Sabet et al., 2013). measured the shear viscosity of CNC dispersions as a function of the shear rate. At a concentration of $1 \mathrm{wt} \%$ and shear rates between 0.1 and $1 \mathrm{~s}$, the measured viscosity was found to be 10-100 mPas. Common ways to access the viscosity of nanocellulose suspension is by using Couette-type rheometer, extensional viscometer, cone and plate rotational viscometer and rolling ball viscometer; or alternate methods that avoid wall depletion effects such as serrated plate system and vane system (Hubbe et al., 2017).

These broad and versatile properties of nanocellulose originate because of the size and chemistry introduced by scaling down to nanometer (Thomas et al., 2018). Due to these attractive properties, nanocellulose can have diverse range of applications that can solve major challenges of sustainable society.

\section{DEVELOPMENT OF NANOCELLULOSE}

In this section, various methods of nanocellulose preparation are summarized.

\subsection{Pre-treatment Methods for CNF}

The purpose of employing pre-treatment methods on wood cellulose is to reduce the consumption of energy during the nano-fibrillation process (Khalil et al., 2014) as shown in Figure 3. Pre-treatment also improve the fibrillation process with an enhanced productivity rate of nanofibres. The pretreatments of cellulosic fibers improve the accessibility of hydroxyl groups, increase the inner surface, and further alter the crystallinity of the fibers leading to breakage of hydrogen bonds of cellulose (Khalil et al., 2014). It involves various hydrolysis and those are summarized here.

\subsubsection{Enzyme Hydrolysis}

The enzymes can hydrolyse selective components. The lignocellulosic fibres consist of various organic compounds which cannot be degraded by a single enzyme. Hence, a set of enzymes is required that make the process more complex (Nasir et al., 2014).

The following sets of enzymes for defibrillation are A and B type cellulases which attack the crystalline part of the cellulose; $C$ and $\mathrm{D}$ type cellulases that are specifically attacking the disordered structure of cellulose (Henriksson and Berglund, 2007).

Paakko et al. (2007) showed the production of nanofibrillated cellulose (NFC) from bleached softwood pulp. The method incorporated mild enzymes (Cellulases $\mathrm{C}$ and $\mathrm{D}$ ), followed by refining and homogenization (Paakko et al., 2007).

\subsubsection{Alkaline-acid}

The most commonly used method is alkaline-acid pre-treatment which involves the solubilisation of lignin, hemicellulose, and pectin before employing a mechanical process for the isolation of CNF (Wang and Sain, 2007).

The alkaline-acid method comprises of three steps as follows (Bhatnagar and Sain, 2005): 


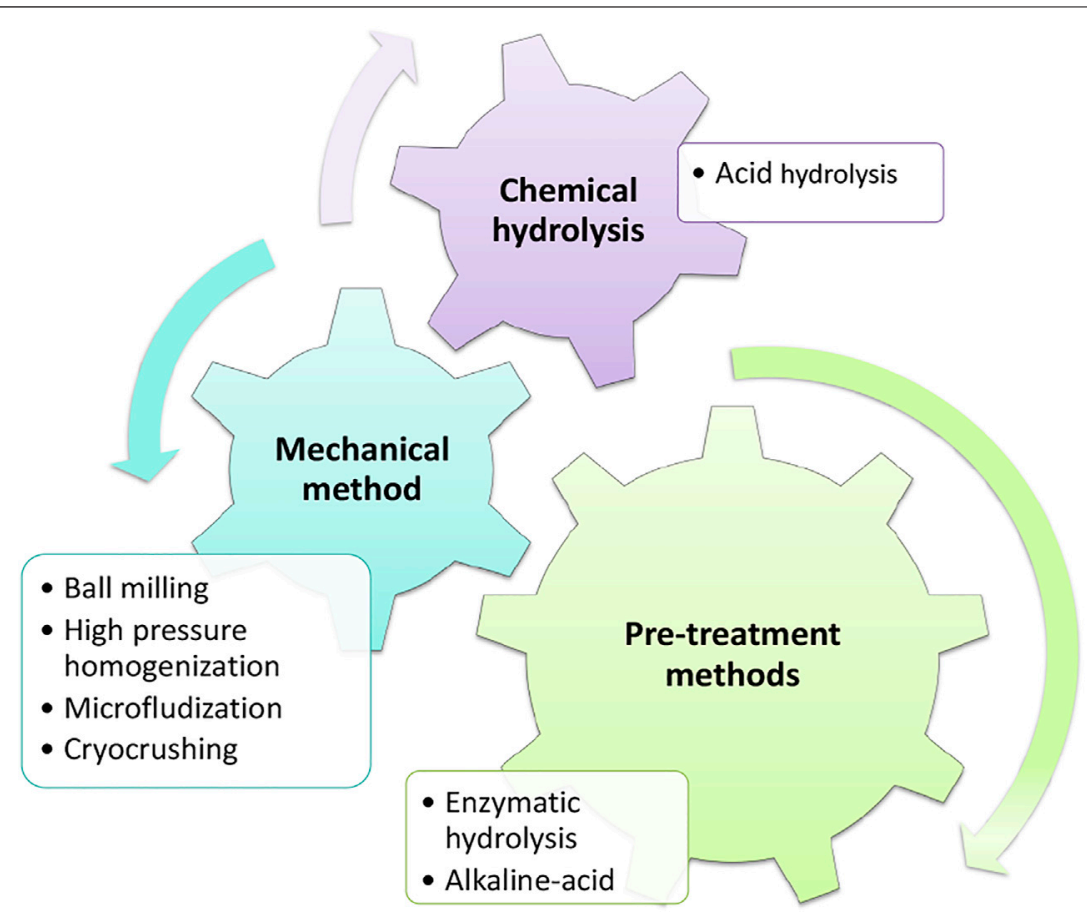

FIGURE 4 | Schematic representation of microfludizer.

1) Alkali treatment: It involves soaking of fibers in $12-17.5 \mathrm{wt} \%$ of sodium hydroxide solution for $2 \mathrm{~h}$ which increases the surface area of the fibers and facilitates the hydrolysis

2) Acid treatment: Further, treated fibers are mixed in $1 \mathrm{M}$ hydrochloric acid solution at $60-80^{\circ} \mathrm{C}$. This process allows the solubilisation of hemicelluloses.

3) Sodium hydroxides $(\mathrm{NaOH})$ : Finally, the material is again treated with $2 \mathrm{wt} \%$ alkali solution for $2 \mathrm{~h}$ at $60-80^{\circ} \mathrm{C}$ which disintegrate the linkages between the carbohydrate and lignin.

Alkaline acid pre-treatment is an efficient method that tends to improve cellulose yield from 43 to $84 \%$ (Alemdar and Sain, 2008).

\subsection{Mechanical Process}

The defibrillation of cellulosic materials through mechanical process requires pre-treatment processing to facilitate the process in an efficient manner (Chauhan and Chakrabarti, 2012). Numerous mechanical processes are available for converting cellulose to nanocelluloses which are as follows (Zuluaga et al., 2007):

\subsubsection{High-Pressure Homogenization}

$\mathrm{HPH}$ is an effective method for the fibrillation of cellulosic fibers to prepare CNF. $\mathrm{HPH}$ is a simple process and does not involve the utilization of any organic solvents (Keerati et al., 2009). In this process, the pulp of cellulose is passed through a nozzle with high pressure (50-2000 MPa) which generates the shear rate in the stream and facilitates the reduction in the size of the fibres (Frone et al., 2011). The schematic representation is given in Figure 4.

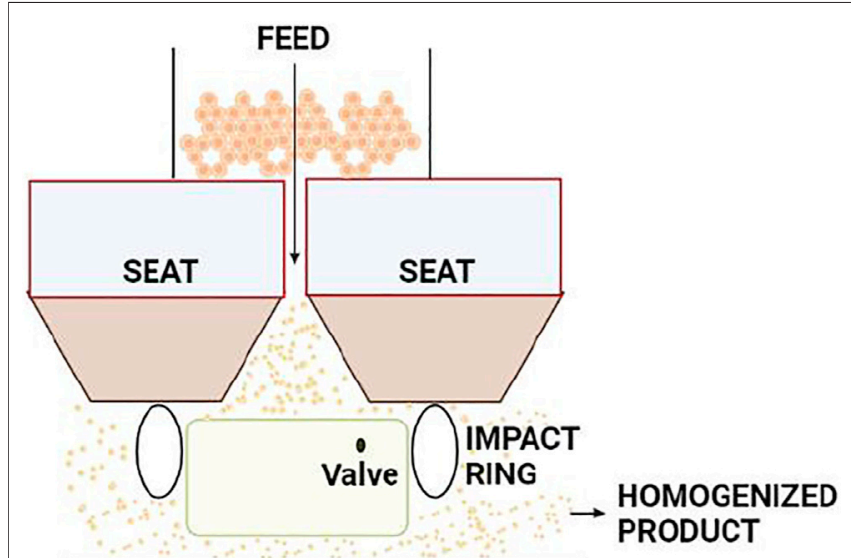

FIGURE 5 | Microfludizer schematic.

The cellulose fibres reduction can be achieved through large pressure drops, high shear forces, turbulent flow and interparticle collision. The extent of pressure applied and the number of homogenization cycles play a critical role in cellulose fibrillation. Habibi et al. performed homogenization of cellulosic material such as cotton, sugar beet and mangosteen rind at $50 \mathrm{MPa}$ at a temperature below $95^{\circ} \mathrm{C}$ with 15 cycles of homogenization (Habibi et al., 2010).

There are some drawbacks associated with $\mathrm{HPH}$ such as fiber clogging and high energy consumption to overcome such problems pulp can be subjected to chemical purification or 


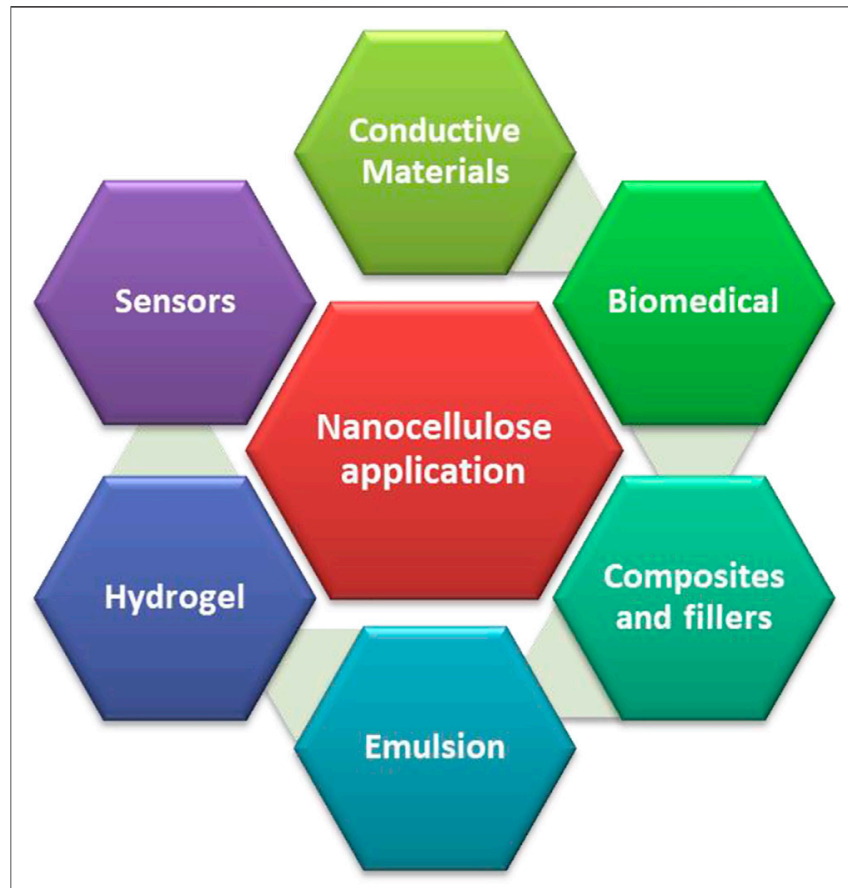

FIGURE 6 | Application of nanocelluloses in various fields.

pre-treatment. Also, excessive mechanical damage occurred in the crystalline structure of CNF (Rebouillat et al., 2013).

\subsubsection{Microfluidization}

Microfluidizers work on the same principle of $\mathrm{HPH}$ in the production of nanocellulose fibers. In contrast to the homogenizer which operates at constant pressure, the microfluidizer function at constant shear rate. It involves an intensifier pump which enhances the pressure whereas the interaction chamber generates the shear and impact forces against the colliding particles to defibrillate the fibres as depicted in Figure 5 (Ferrer et al., 2012). Lee et al. demonstrated that the aspect ratio of cellulose fiber was increased after 10-15 passing cycles whereas additional 20 cycles may cause agglomeration of CNFs due to the higher surface area (Lee et al., 2009).

\subsubsection{Grinding}

Grinding is another process of breaking the cellulose to nanoform. The pulp is passed through a couple of stones, in which one stone is fixed and the other stone rotates which provides the shear force to break down the hydrogen bond of the fibres (Iwamoto et al., 2007; Siro and Plackett 2010).

Wang and Drzal (2012) utilized the commercial stone grinder to generate the nanocellulose fibrils from the bleached pulp of eucalyptus. Scientists studied the relation between energy consumption and fibrillation time of the fibres as a function of crystallinity. The friction between the stones generates heat which leads to the evaporation of water content and increases the solid content.

\subsubsection{Cryocrushing}

Another mechanical method is cryocrushing in which fibers are soaked in water and cellulose absorbs water in its cavity. The water-soaked cellulose is then immersed in liquid nitrogen that rapidly solidifies the water content of the cellulose, and is subsequently crushed by mortar and pestle (Frone et al., 2011). Wang and Sain (2007) investigated the $\mathrm{HPH}$ and cryocrushing processes together to develop nanofibers from soybean stock and reported that the diameter of nanofibers lies in the range of $50-100 \mathrm{~nm}$ after examine through transmission electron microscopy (TEM).

\subsubsection{Ball Milling Process}

Ball milling is a mechanical process in which the cellulose suspension is added into the cylindrical container along with the milling material viz. balls (comprised of ceramic, zirconia, or metal), the container rotates in a clockwise and anticlockwise direction and collision of balls with the cellulose tends to defibrillate the fibres. Zhang et al. (2015) studied various parameters playing a crucial role in the nanocelluloses formation such as ball size, ball-to-cellulose weight ratio, grinding time, moisture content, and carboxylic charge. The report showed the synthesis of $100 \mathrm{~nm}$ cellulose nanofibres with cerium-doped zirconia balls of $0.4-0.6 \mathrm{~mm}$ in diameter in $1.5 \mathrm{~h}$ without the alkaline pre-treatment. Gbadeyan et al. (2020) showed the synthesis of nanoparticles using wet ball milling at $450 \mathrm{rpm}$ for $258 \mathrm{~min}$ in a clockwise direction.

\subsection{Chemical Hydrolysis}

The chemical process involves the hydrolysis through the acid where the hydronium ion enters the amorphous regions of cellulose chains and promotes the hydrolytic cleavage of the glycosidic bonds. Various other strong acids that efficiently degrade the cellulose fibres into a nano-form such as hydrochloric and sulfuric acids have been extensively studied. To prepare crystalline cellulosic nanoparticles, phosphoric acid, as well as hydrobromic and nitric acids have been recommended (Liu et al., 2010).

The advantage of utilizing sulfuric acid is that it initiates the esterification process on the cellulose surface and promotes the grafting of anionic sulfate ester groups. Further, the anionic group induces the production of a negative electrostatic layer on the surface of the nanocrystals and helps their dispersion in water (Roman and Winter, 2004).

The major drawback of acid hydrolysis is a huge amount of acid wastewater generated from the washing process. The washing is performed generally by adding cold water followed by centrifugation to neutralize the $\mathrm{pH}$ value of the nanocellulose suspension (Johar et al., 2012). Further, dialysis was also performed to remove the residual acids. Numerous drawbacks associated with dialysis are: time-consuming, require a significant amount of water which make the overall process less environmentally friendly and causes health hazard (Nirmal et al., 2020). 


\section{APPLICATIONS OF NANOCELLULOSE}

Nanocellulose is an alternative biomaterial to synthetic materials that are environmentally friendly, and biodegradable. Recently, cellulose nanocomposites are utilized in medical, automotive, electronics, packaging, construction, and wastewater treatment applications (Figure 6).

\subsection{Nanocellulose Derived Conductive Materials}

Nanocellulose can be integrated with the conductive materials viz. metal particles, carbon materials, and conductive polymers to fabricate conductive composites which have high stiffness, flexibility and mechanical strength and flexibility (Pottathara et al., 2016). The Nanocellulose based conductive composite fabrication has been achieved through surface grafting and blending of Nanocellulose and conductive species (Ko et al., 2017).

The blending procedures involve mixing the different materials in such a way that the strength and charge transfer of individual materials can be controlled. Recently, conductive carbon nanomaterials and metallic nanoparticles have been merged with nanocellulose to generate the hybrid material ( $\mathrm{Du}$ et al., 2017). It serves as green and biodegradable flexible conducting polymers that have potential applications in electrodes and display devices (Shi et al., 2013).

Wang et al. reported that core-shell structured PANI/CNF develop strong synergistic interactions with the soy protein isolated through tannic acid cross-linking. The network offered enhanced electric conductivity of $0.078 \mathrm{~S} . \mathrm{m}-1$ and improved structural stability that makes the nanofilms appealing for green energy-storage systems (Wang et al., 2019).

\subsection{Nanocellulose in the Biomedical Field}

Nanocellulose is an efficient biomaterial for medical application because of its low toxicity and excellent biocompatibility, as well as self-assembly behaviour, rheology and surface chemistry (Yan et al., 2017; Du et al., 2019). Though, it is evident that the bacterial nanocellulose is non-toxic, whereas, the toxicity of other cellulose nanoparticles is less explored. The properties of nanocellulose and surface chemistry are used in the synthesis of scaffolds for improving proliferation and differentiation of cells and cell adhesion (Plackett et al., 2014).

Cellulose nanocrystals and bacterial nanocellulose are ideal for tissue engineering scaffold because of surface chemistry, low cytotoxicity, high porosity and 3D network (Raghavendra et al., 2015). Nanocellulose can be used as a delivery compound in the form of tablet coatings, membranes, and biopolymer delivery systems. As nanocellulose can provide better drug stability and controlled drug release into the system (Bacakova et al., 2019). Jackson et al. studied the utilization of cellulose nanocrystals as a carrier to bind with water-soluble drugs such as doxorubicin and tetracycline. Around $80 \%$ of drugs were released in the first minute and only $20 \%$ accounted for sustainable release in the next 4 days (Jackson et al., 2011). Nanocelluloses was also used as a coating material (Bacakova et al., 2019), electrospun nano-fibers (Khalil et al., 2012), membranes and hydro-gels (Kabir et al., 2018; Yue et al., 2019).

Nanocellulose is also used as a wound dressing material explicitly, bacterial cellulose, Bioprocess ${ }^{\circledR}$, Biofill $^{\circledR}, \mathrm{XCell}^{\circledR}$ and Nanoskin ${ }^{\circledR}$ are a few instances of accessible items (De Olyveira et al., 2011; Gatenholm, 2011). The two commercial products are utilized in the treatment of skin wounds and ulcers as transitory fake skin. Gengiflex ${ }^{\circledR}$, other item accessible, is applied in treatment of periodontal sicknesses. These products permit a fitting hydration and assimilation, keeping up with the best dampness balance needed for a decent recuperating measure (Thakur, 2014).

There has been an expanding interest in the advancement of nanocellulose-based biomaterials for delicate tissue substitution and reconstruction. Bodin et al. analysed the mechanical properties of Bacterial Nanocellulose (BNC) gels with collagen meniscal inserts and pig menisci harvested from pigs. They tracked down that the mechanical properties of the BNC gel were comparable in size to the ones of pig menisci. The E' value of the $\mathrm{BNC}$ gel was estimated to be $1 \mathrm{MPa}$; this was multiple times higher than the one of the collagen material, $0.01 \mathrm{MPa}$ in tensile load. The mix of economical materials, controlled meniscus shape, and promising cell movement makes BNC materials an alluring contender for future meniscus embed applications (Bodin et al., 2007).

Another innovative potential of nanocellulose material is its utilization in tissue engineering. Due to the extraordinary threedimensional (3D) network structure of cellulose and its mechanical properties and expected biocompatibility, cellulose is an optimal material possibility for an assortment of tissue designing applications. A report showed the biocompatibility of BNC in cell culture (Ugrin et al., 2021). In the study, another mammalian cell culture substrate was created with an Acetobacter aceti delivered BNC. In this research, the authors showed that a serum-soaked BNC film was a viable substrate for use in tissue designing. The geology and design of tissue designing platforms (i.e., surface porosity, fiber network structure, surface geography, and fibre thickness) are fundamental parts that impact the cell-biomaterial interaction and, therewith, the cells behaviour (Jorfi et al., 2014).

\subsection{Nanocellulose in Wood Adhesives}

Another application is reported on the application of nanocellulose in wood adhesives (Lengowski et al., 2019). The plywood panels are made up of wood overlapping and bonded with one another through synthetic adhesives such as phenolformaldehyde and urea-formaldehyde under pressure and temperature. The advantages of using nanocellulose as reinforcements in adhesives for wood panel products are the chances of altering the properties of adhesives, improvement of mechanical and physical strength. Along with that, the viscosity can be altered by changing the concentration of CNC (Damasio et al., 2017).

Majorly, wood adhesives are categorized into two groups such as soft and brittle adhesives. The report of Stoeckel et al. (2013) showed that iso-cyanate containing adhesives and polyethylene- 
vinyl acetate including epoxies are less rigid than that of aminobased and phenolic-based adhesives. To overcome this, the addition of high-stiffness and high-surface-area of nanocellulose into the soft polymers led to the stiffening of cured modified adhesive due to the rapid increase in the viscosity of the adhesive (Veigel et al., 2012). The nanocellulose fills the hole and irregularities in the surface of the wood surface by the reduction in the porosity (Ayrilmis et al., 2019).

\subsection{Nanocellulose in Cosmetics}

The cosmetic industry is an ever-growing sector but they have an extensive environmental impact because of the utilization of nonrenewable and non-biodegradable raw materials such as plastic microbeads were used as decoratives and parabens as preservatives. Thus, there is a need to develop green tech solutions by replacing synthetic ingredients with bio-based counterparts (Ludwicka et al., 2016).

Nanocellulose is also incorporated in the cosmetics products such as mask packs and other specific cosmetics. Nanocellulose tends to disperse in water and have a high aspect ratio. These properties make it easier to overlap, which affects the viscosity and facilitates the gelation at a lower temperature (Risti et al., 2011; Ludwicka et al., 2016).

Other products such as nanocellulose mats are used in cosmetics for peeling, laser therapy, mesotherapy, atopic facial changes, and microdermabrasion. Cellulose nanocarrier integrated with the proteolytic enzymes can be utilized as a skin peeler which is typically linked with amino acids that serve as good nutrients for the neck and face (Ludwicka et al., 2016).

\subsection{Nanocellulose Used as an Optical Material}

Nanocellulose can be integrated into the photonic application, the liquid crystalline behaviour of cellulose nanocrystals (CNCs) subsequently led to the opalescent films which have optical characters. The flexibility of the material depends on two parameters: the structure and surface chemistry of the cellulose. Nanocellulose is utilized as a host for optically active nanoparticles. CNCs can easily develop coloured, chiral films through evaporation of the aqueous suspensions. The chiral nematic mesoporous cellulose (CNMC) from CNC-silica composites was developed which showed high surface areas (up to $314 \mathrm{~m}^{2} \mathrm{~g}^{-1}$ ) and large average pore widths (up to $15.7 \mathrm{~nm}$ ) along with that it also have high degree of crystallinity when compared with pure CNC films indicating no adverse effect of the preparation process. Further, the developed materials were used to stabilize gold nanoparticles and also represent chiroptical properties due to the interaction of the surface plasmon resonance of the gold nanoparticles with the chiral nematic environment provided by the CNMC host (Schlesinger et al., 2015).

The liquid crystals of cellulose exhibited right hand and lefthand chirality whereas the chiral nematic organization of CNCs is always left-handed which is due to the result of underlying right- handed chirality. Thus, chiral nematic CNC films selectively reflect left-handed light and appeared colourful (Bardet et al., 2015).

\subsection{Nanocellulose Composites and Fillers}

Nanocellulose has numerous properties (nanoscale dimension with gas and water barrier properties) which make it a suitable aspirant of reinforcement (Nair et al., 2014). It serves as an agent for the development of bio-nanocomposites such as films, coatings and foams etc. The report of Dufresne et al. (2013) stated about the improvement in the mechanical properties of a nano composite developed from the potato-starch as polymer matrix and nano fiber cellulose as a reinforcing agent.

Yue et al. showed that utilization of modified CNCs enables the interlocking points in the epoxy matrix restricting the mobility of chain, and homogeneity that eventually improves the filler-matrix dispersion contributing to the enhanced storage modulus and glass transition (Yue et al., 2019).

Nakagaito and Yano (2008) showed the enhanced tensile properties of the phenol-formaldehyde resin combined with nanofiber cellulose. A similar study of hydroxypropylated cellulose was reported by Zimmermann et al. (2010). Another study showed the saturation of nanopaper using melamineformaldehyde (MF) (Henriksson et al., 2007).

\subsection{Nanocellulose in Packaging Industries}

Nanocellulose is a renewable source obtained from lignocellulosic waste thus; make it cost-effective, non-toxic for food packaging. Few reports showed the utilization of nano-biocomposite film for the packaging material along with the nano-clay and polylactic acid (PLA) matrix which further improves the water and oxygen barrier properties (Trifol et al., 2016).

PLA films with CNCs (treated with or without surfactant) and silver nanoparticles were developed through melt extrusion. The silver nanoparticles act as an antibacterial agent that inhibits the growth of gram positive and gram negative bacteria, whereas, the presence of surfactant facilitate the tensile strength of the matrix (Azeredo et al., 2017).

Numerous reports demonstrated that the functionalization of nanocellulose incorporates additional properties on the structure (Azeredo et al., 2017; Silva et al., 2020). Dong et al. modified CNFs by applying TEMPO oxidation which imparts carboxylate groups that were easily accessible for binding with silver nanoparticles. These nanoparticles compact the CNF coalescence in the films due to the carboxylate-Ag binding reduced the water solvation and hydrogen bonding between the CNFs also acts as an antibacterial agent that could be exploited for food packaging applications (Dong et al., 2013).

\subsection{Nanocellulose as Ion Exchange Membrane}

Another application involves the utilization of nanocellulose in the form of an ion-exchange membrane. Jiang et al. (2015) suggested proton-exchange membrane for fuel cells and direct methanol fuel cell can be developed using bacterial nanocellulose. Razaq et al. (2011) showed the preparation of Polypyrrole- 
nanocellulose membranes through the oxidation of pyrrole monomer onto the cellulose nano-fibres. These membranes have efficient porosity and represented reversible electrochemically controlled ion exchange.

Vilela et al. investigated nanocellulose/lignosulfonates based ion-exchange membrane to develop sustainable separators for polymer electrolyte fuel cells. The bacterial nanocellulose was combined with lignosulfonates obtained from the sulphite pulping process into three-dimensional structures to produce an ion-exchange membrane. The separator showed good thermal-oxidative stability up to $200^{\circ} \mathrm{C}$ in the presence of $\mathrm{N} 2$ and $\mathrm{O} 2$ respectively and mechanical properties with young's modulus of 8.2 GPa.Thus, these ion conductors represent an environmentally friendly alternative to conventional counterparts (Vilela et al., 2020).

\subsection{Nanocellulose Used in Adsorption}

$\mathrm{Yu}$ et al. (2013) represented that integration of succinic acid moieties onto CNCs tends to improve the binding efficacy to $\mathrm{Cd}^{2+}$ and $\mathrm{Pb}^{2+}$ in the aqueous solution. These adsorbing properties make it a suitable candidate for water purification.

Further, a novel form of adsorbent of cellulose and maleic anhydride was developed to remove $\mathrm{Hg}$ (II) ions. To enhance the adsorption efficiency the amorphous domain of the cellulose need to be removed which further support the accessibility of the hydroxyl group on the surface of cellulose. During the production of CNCs through sulphuric acid hydrolysis, it imposes the sulphate linkages on the surface which also serve as binding sites for the heavy metals (Mohammed et al., 2018).

Nanocellulose introduced with magnetic nanomaterials appeared to be an excellent composite adsorbent with magnetic properties. The core-shell cellulose magnetite biosorbent can bring about the adsorption of congo red. The benzyl group of the cellulose structured are accountable for the magnetic nature of the polymeric ionic liquid that was created by the reaction between the epichlorohydrin and 1-methylimidazole. Additionally, the functionalization could improve its aromatic character and anion exchange properties.

Cellulose based $\mathrm{Fe} 3 \mathrm{O} 4$ polymeric ionic liquid was developed which have the efficient magnetic biosorbent property used for congo red adsorption. The adsorbent was prepared using one step synthesize of core shell magnetic cellulose with epichlorohydrin and methylimidazole. The nanohybrid represents the fast adsorption kinetic as well as isotherm studies (Beyki et al., 2016).

\subsection{Nanocellulose as a Hydrogel}

The nanocellulose has mechanical strength and rigidity which makes it efficient filler in hydrogel nanocomposites. Many reports showed the amount of cellulose required for the generation gellike consistency. The CNC-based hydrogels showed interesting bioavailability that provides superior drug delivery capacity due to their high surface area and open-pore structure (Urena et al., 2011). The report showed the development of a novel nanocomposite hydrogel using $\mathrm{CNCs}$ and chitosan and employed it as a carrier for the controlled delivery of theophylline (Way et al., 2012).
Reports demonstrated that around $10 \mathrm{wt} \%$ of $\mathrm{CNCs}$ will transit into an aggregated gel-like phase. These gels can be developed through destabilization of CNC suspensions with salt or acid or cross-linking CNCs with multivalent ions or chemical bonds. The gelation may be manipulated through a number of parameters such as solution conditions, surface modifications, and adsorbing or non-adsorbing water-soluble polymers (De France et al., 2017).

Chau et al. reported that the properties of developed nanofibrillar $\mathrm{CNC}$ gel by the addition of cations with different charge numbers and ionic radii to aqueous $\mathrm{CNC}$ suspensions. Due to the addition of ions with higher charge number tends to reduce the Debye length of the CNCs, thus, facilitating their interaction in the CNC network which led to enhance the stiffness. Furthermore, the association between the sulphate groups of $\mathrm{CNCs}$ by the metal cations with higher ionic radii also contributes in the gelation. The CNC gels have tendency to vary the mechanical properties without significantly affecting the mesh size is serve as an advantage of ion-mediated gelation, in comparison with changing $\mathrm{CNC}$ concentration in suspensions (Chau et al., 2015).

\subsection{Structuring of Nanocellulose at Liquid-Liquid Interfaces: Emulsions}

A well-known phenomenon associated with nanoscale particles at their interface are self-assembly which tends to stabilize the emulsions and such emulsions are known as pickering emulsions. Cellulose nanoparticles also represent similar properties at the oil-water interface. The major reason for selecting nanocellulose in emulsion stabilization is their low toxicity and biocompatibility (Tingaut et al., 2012).

Capron reported that unmodified CNCs can effectively adsorb oil-water interfaces and develop deformable and highly stable oilin-water emulsions, showing the amphiphilic character of CNCs (Capron, 2018).

\subsection{Nanocellulose in Sensing}

Nanocellulose possesses properties such as photonic, colloidal, and surface properties which make it suitable for sensors (Golmohammadi et al., 2017). Nanocellulose is also an ecofriendly and non-toxic aspirant for biosensing. The report of Mangayil et al. (2017) reported the bacteria cellulose film extracted from Komagataeibacter xylinus species have intrinsic piezoelectricity hence, make it piezoelectric sensors (Verma et al., 2014). The study of Golmohammadi et al., 2017 analytically determines how nanocellulose is designed and implemented in the biosensing technology.

To sense various analytes in drug delivery, CNCs have been labelled with fluorophores. The investigation analysed the development of dual fluorescent labelled CNCs for $\mathrm{pH}$ sensing. The study demonstrated the binding of fluorescein isothiocyanate (FITC) and rhodamine B isothiocyanate (RBITC) with CNCs does not impact the crystallinity and morphology of CNCs. The FITC and RBITC were attached with CNCs in $0.1 \mathrm{M} \mathrm{NaOH}$ at room temperature for $72 \mathrm{~h}$ under dark. After the reaction, the amount of FITC and 
RBITC linked to CNCs were 2.8 and $2.1 \mu \mathrm{mol} \mathrm{g}{ }^{-1}$, respectively. When the system is exposed to the varying $\mathrm{pH}$ it tends to change the color of the solution from white to pink. Fluorescence emissions of the sensing solution were responded to the variation in the $\mathrm{pH}$ (Nguyen et al., 2019).

The capability of the biosensors to estimate the enzymes in trace amounts is vital in various biomedical fields. The surface of CNCs was modified by immobilization of peptides to improve the surface area and sensitivity of sensors. Human neutrophil elastase (HNE) hydrolysed to n-succinyl-alaninevaline-para-nitroanilide (tripeptide) which is covalently attached to CNCs, releasing a colored dye (para-nitroaniline). The colored dye can be estimated spectrophotometrically to determine the amount of HNE in the system. The report was confirmed that CNC sensors were more reactive (10 to 20 folds) towards HNE when compared with the paper sensors because of the increased surface area of the CNCs (8,000 folds). CNC based sensors were successfully detected HNE activity in $50 \mathrm{mU} \mathrm{mL}^{-1}$ wound fluid (Edwards et al., 2016).

\section{LIFE CYCLE ASSESSMENT}

Environmental impacts associated with nanocellulose production vary widely based on feedstock, technology, and end products. Bio-based raw material is not a sufficient condition to ensure that the nanocellulose production process is sustainable. Current technologies for nanocellulose production constitute multiple steps that are energy-intensive and employ harsh operating conditions (Dhali et al., 2021). For example, most research studies have employed bleached pulp obtained from chemical pulping and purification as feedstock to produce nanocellulose (Jiang et al., 2021). However, chemical pulping uses harsh chemicals and large quantities of water that will contribute adversely to environmental impacts. These impacts are not captured in conventional environmental impact assessment (EIA) studies. Life cycle assessment (LCA) is a holistic approach that quantifies the direct and indirect environmental impacts by taking a cradle-to-grave scope. The LCA methodology is formalized through the ISO 14040 framework and is being increasingly used to assess novel products and processes. Here, important insights gained from LCA studies in literature are summarized.

For CNCs, energy demand was reported to significantly affect the overall impacts, greenhouse gas (GHG) emissions, in particular. Energy demands of CNCs production from different feedstocks and production routes varied from 457 to $15,943 \mathrm{MJ}$, and corresponding global warming potential (GWP) ranged from 12.9 to $1,086 \mathrm{~kg} \mathrm{CO}{ }^{2}$ eq. $/ \mathrm{kg} \mathrm{CNC}$ (Zargar et al., 2021). De Figueirêdo et al. (2012) employed acid hydrolysis of two different feedstocks i.e., cotton fibers and coconut fibers for CNC production. Energy consumption for coconut fibers was reported to be an order of magnitude higher at $16,000 \mathrm{~J} / \mathrm{kg} \mathrm{CNC}$ compared to that for cotton fibers ( $1800 \mathrm{~J} / \mathrm{kg}$ CNC production). Consequently, associated GHG impacts for coconut fibers and cotton fibers were 1,086 and $122 \mathrm{~kg} \mathrm{CO} \mathrm{CO}^{2}$ eq. $/ \mathrm{kg} \mathrm{CNC}$, respectively. In addition to being highly energy intensive, CNCs isolation involves chemicals that lead to other environmental impacts (Trache et al., 2020). For CNCs, although sulfuric acid is conventionally utilized for acid hydrolysis, developing cost-competitive production routes that employ organic acids can be a way forward (Bondancia et al., 2020). However, the weak nature and higher $\mathrm{pKa}$ value mean that organic acids are required in larger quantities as compared to mineral acids. This can completely offset the benefit. Optimizing the acid selection, quantity and designing the acid/chemical recovery system is important. Additionally, enzyme-mediated isolation that requires mild conditions and a potential environmentally benign option should be further explored (Arantes et al., 2020). The influence of feedstock on energy demand and GHG impacts was demonstrated in the by De Figueirêdo et al. (2012).

For CNFs, energy demands in the literature ranged from 87 to $19,000 \mathrm{MJ}$, and the GWP was reported to be between 0.79 and $800 \mathrm{~kg} \mathrm{CO}{ }^{2}$ eq. $/ \mathrm{kg}$ CNF (Zargar et al., 2021). High energy demands of CNF production from mechanical treatments pose a major concern, even though these methods are suitable for scaling. In this context, chemical and enzymatic pretreatment have been proposed to overcome the critical challenges of employing mechanical treatment alone (Negi et al., 2019). However, a scenario with chemical pretreatment resulted in higher impacts in the categories of global warming potential, water depletion, cumulative energy demand, and terrestrial acidification (Arvidsson et al., 2015). In comparison, enzymatic pretreatment reduced the energy usage by $64 \%$ compared to a scenario without any pretreatment. Emissions associated with enzymatic pretreatment reduced to $0.79 \mathrm{~kg} \mathrm{CO}^{2}$ eq. $/ \mathrm{kg}$ CNF compared to chemical pretreatment with $99 \mathrm{~kg} \mathrm{CO}^{2}$ eq./kg CNF. Another potential alternative could be employing mild treatments to produce lignin-containing cellulose nanomaterials (Ewulonu et al., 2019; Zargar et al., 2021).

Due to the lack of pilot plant or industrial-scale data, lab-scale data of nanocelluloses production has often been used in the environmental assessment of nanocelluloses. Even though early assessment of lab-scale data is essential to identify the process hotspots, results from such studies cannot be competitive with the nanocellulose counterparts produced at an industrial scale with optimized and well-established processes (Piccinno et al., 2018). Particularly for the production of CNFs that is energy-intensive, several authors reported significant overestimation of electricity consumed for lab-scale (Bartolozzi et al., 2020; Gallo Stampino et al., 2021). Sensitivity analysis of electricity consumption revealed that though results did not vary qualitatively, impacts were drastically affected from a quantitative perspective. Therefore, in the absence of pilot-scale data, a scale-up framework (Piccinno et al., 2015; Piccinno et al., 2018; Bartolozzi et al., 2020) has to be adopted to model the industrial scale nanocellulose production.

Many LCA studies in the literature overlooked the environmental and biological toxicity impacts of nanocellulose (Li et al., 2013; Jiang et al., 2021). Scope of these LCA studies should consider the environmental release and human exposure of nanocelluloses in the inventory modeling for completeness. However, lack of appropriate characterization factors specific to nanomaterials that 
determine toxicity-related potential impacts poses an additional challenge (Salieri et al., 2018). To this end, environmental risk assessment studies (Lazarevic and Finnveden, 2013; Jiang et al., 2021) and development of specific characterisation factors for ecotoxicity impacts should be at the forefront of future studies. Thus, extending the scope of LCA from "cradle to gate" approach to "cradle to grave" can provide a better estimation of the overall impacts associated with nanocellulose based materials. A comprehensive LCA study should also take credit for avoided impacts. In this approach, the impacts for the production of conventional product that the nanocellulose is replacing are deducted, giving a net difference.

\section{TECHNO-ECONOMIC ASSESSMENT}

Production cost depends on the pretreatment method, acid used for hydrolysis, and the feedstock cost. Production costs reported in literature varies widely from 2,000 to 10,000 USD/ton (de Assis et al., 2017; Jiang et al., 2018; Blair et al., 2021). CNC production via conventional sulfuric acid hydrolysis mandates acid-resistant equipment that increases the capital expenditure (CAPEX). Moreover, acid recovery via neutralization and effluent treatment further increases the CAPEX. A study on CNCs reported that the manufacturing costs for sulfuric acid hydrolysis varied from 3,632 to 4,420 USD/dry ton (de Assis et al., 2017). In all scenarios under consideration, dissolving pulp was reported as the primary cost driver contributing to $38-45 \%$ of manufacturing cost. For a configuration with no acid recovery, acid and lime costs accounted for $24-28 \%$ of manufacturing cost. Upon acid recovery, this contribution drastically decreased to $3-4 \%$ of manufacturing cost. The minimum selling price (MSP) of CNC was majorly influenced by CAPEX and the cost required for dissolving pulp. An increase in CAPEX due to acid recovery increased the MSP from 4,829 to 5,125 USD/dry ton (de Assis et al., 2017). A recent TEA study reported equipment cost contributed to $65 \%$ of CAPEX, with chemical recovery section specifically accounting for 22\% of CAPEX (Blair et al., 2021). This study reported a relatively lower MSP at 1,656 USD/ton, explained by the lower feedstock handling cost. This production route benefitted from the less energy-intensive mechanical processing coupled with SO2-ethanol-water pulping. Additionally, employing wood chips as feedstock rather than chemical pulp can benefit the process economics due to co-product credits. In another study that reported CNCs obtained via citric acid hydrolysis, a better alternative than sulfuric acid from an environmental perspective, the MSP was relatively higher at $16,460 \mathrm{USD} /$ dry ton (Bondancia et al., 2020). CNC production using citric acid hydrolysis displayed a relatively lower capital cost at seven million USD. Whereas, operating costs were higher at 8.25 million USD, with citric acid alone contributing to $40 \%$ of this cost even at $89 \%$ acid recovery. It was estimated that for a $79 \%$ decrease in citric acid market price i.e., at 290 USD/ton, MSP of CNC produced using citric acid and sulfuric acid would be equivalent. Upon observing the MSP with a chemical recovery section and citric acid hydrolysis, it is noteworthy that there is a trade-off between economic and environmental aspects of nanocellulose production.

Currently, nanocelluloses are not cost-effective compared to their alternatives due to low production capacities. Shen et al. (2020) discussed the factors inhibiting the commercialization of nanocellulose reinforced polymer composites. Authors reported that pretreatment costs and low production capacities associated with nanocelluloses resulted in substantially higher production costs compared to the alternatives such as nanomontmorillonite and nanosilica. In this context, it is essential to achieve mass production through process optimization for nanocelluloses commercialization. Moreover, the lack of standardized product index due to inconsistent properties of nanocelluloses produced from comprehensive selection of sources and production routes hinders the nanocelluloses marketization.

To effectively address both the environmental and economic concerns, enzyme-mediated production of nanocelluloses can offer a potential solution. However, it is to be noted that commercial enzymes are often optimized to convert cellulose and hemicellulose fractions to fermentable sugars. These issues demand further research on optimizing enzyme cocktails for nanocellulose production (Arantes et al., 2020) and the on-site production of enzymes to increase the economic viability (Squinca et al., 2020). Most studies on nanocellulose production employed bleached chemical pulp or purified cellulose that already lost $50-60 \%$ of the biomass content for nanocellulose production (Jiang et al., 2021). This practice results in less efficient utilization of biomass due to reduced nanocellulose yields with respect to original biomass. In comparison, mechanical pulp can serve as an efficient alternative and needs further investigation. Furthermore, research efforts have to be focused on optimizing the reaction yield that will improve the overall economics of the production route. Moreover, developing technologies that are feedstock agnostic can play a crucial role in enhancing the production scale. In such a scenario, economies of scale can be leveraged to achieve cost-competitive production. To achieve sustainable nanocellulose production, routes with mild reaction conditions and single-step extraction processes should be the focus of future research studies.

\section{CONCLUSION AND FUTURE PERSPECTIVES}

Nano cellulose is renewable, non-toxic, environmentally friendly material and recent technologies make it suitable for creating alternatives options in the field of packaging products, biomedical, composites, paper making, water purification, and cosmetics.

The effective design of nano cellulose products suitable for different fields depends on the identification of problems and resolving them. Further, this showed that extensive research is required on the utilization of nano cellulose in various other fields 
as well. The commercial manufacturer of nanocelluloses is dependent on the different end-user requirements and implementation of the product would have encouraging future in terms of expanding global technology development.

With the emerging market for nanocellulose, nanocellulose production such as CNCs and CNFs can benefit from the earlystage environmental and economic assessments. These studies can be instrumental in identifying the hotspots and opportunities for optimization of process energy and chemicals consumption. It is mandatory to address the challenges posed by conventional methods such as the energy-intensive nature of mechanical pretreatment, effluent handling and recovery system for acid hydrolysis, and higher reaction times for enzyme-mediated treatment. In this context, research gaps to be addressed by LCA practitioners and technology developers have been suggested. In addition to eco-toxicology studies of nanocellulose, pretreatment and isolation methods that are scalable, environmentally friendly, and cost-effective have to be investigated further.

\section{REFERENCES}

Abdul Khalil, H. P. S., Bhat, A. H., and Ireana Yusra, A. F. (2012). Green Composites from Sustainable Cellulose Nanofibrils: a Review. Carbohydr. Polym. 87, 963-979. doi:10.1016/j.carbpol.2011.08.078

Abdul Khalil, H. P. S., Davoudpour, Y., Islam, M. N., Mustapha, A., Sudesh, K., Dungani, R., et al. (2014). Production and Modification of Nanofibrillated Cellulose Using Various Mechanical Processes: a Review. Carbohydr. Polym. 99, 649-665. doi:10.1016/j.carbpol.2013.08.069

Agrawal, R., Kumari, P., Sivagurunathan, P., Satlewal, A., Kumar, R., Gupta, R. P., et al. (2021a). "Pretreatment Process and its Effect on Enzymatic Hydrolysis of Biomass," in Current Status and Future Scope of Microbial Cellulases. Editors D.K. Tuli and A. Kuila (Elsevier), 145-169. doi:10.1016/b978-0-12-8218822.00012-0

Agrawal, R., Verma, A., Singhania, R. R., Varjani, S., Di Dong, C., and Kumar Patel, A. (2021b). Current Understanding of the Inhibition Factors and Their Mechanism of Action for the Lignocellulosic Biomass Hydrolysis. Bioresour. Technology 332, 125042. doi:10.1016/j.biortech.2021.125042

Alemdar, A., and Sain, M. (2008). Isolation and Characterization of Nanofibers from Agricultural Residues - Wheat Straw and Soy Hulls. Bioresour. Technology 99, 1664-1671. doi:10.1016/j.biortech.2007.04.029

Alonso-Lerma, B., Barandiaran, L., Ugarte, L., Larraza, I., Reifs, A., Olmos-Juste, R., et al. (2020). High Performance Crystalline Nanocellulose Using an Ancestral Endoglucanase. Commun. Mater. 1 (1), 1-10. doi:10.1038/s43246-020-00055-5

Arantes, V., Dias, I. K. R., Berto, G. L., Pereira, B., Marotti, B. S., and Nogueira, C. F. O. (2020). The Current Status of the Enzyme-Mediated Isolation and Functionalization of Nanocelluloses: Production, Properties, TechnoEconomics, and Opportunities. Cellulose 27 (Issue 18), 10571-10630. doi:10.1007/s10570-020-03332-1

Arvidsson, R., Nguyen, D., and Svanström, M. (2015). Life Cycle Assessment of Cellulose Nanofibrils Production by Mechanical Treatment and Two Different Pretreatment Processes. Environ. Sci. Technol. 49 (11), 6881-6890. doi:10.1021/ acs.est.5b00888

Ayrilmis, N., Ozdemir, F., Nazarenko, O. B., and Visakh, P. (2019). Mechanical and thermal Properties of Moringa Oleifera Cellulose-Based Epoxy Nanocomposites. J. Compos. Mater. 53, 669-675. doi:10.1177/ 0021998318789732

Azeredo, H. M. C., Rosa, M. F., and Mattoso, L. H. C. (2017). Nanocellulose in BioBased Food Packaging Applications. Ind. Crops Prod. 97, 664-671. doi:10.1016/ j.indcrop.2016.03.013

Bacakova, L., Pajorova, J., Bacakova, M., Skogberg, A., Kallio, P., Kolarova, K., et al. (2019). Versatile Application of Nanocellulose: From Industry to Skin Tissue

\section{AUTHOR CONTRIBUTIONS}

PK and NS contributed equally for writing, editing and revisions of this manuscript. RA is chiefly responsible for executing the idea, managing funding and article processing for final submission. MM and YS contributed the TEA, LCA sections. $\mathrm{RR}$ and BA critically reviewed the article and provided valuable inputs for the multiple sections.

\section{ACKNOWLEDGMENTS}

RA is thankful to TERI (The Energy and Resources Institute), Gurugram India for providing all infrastructural, analytical, and financial assistance. The SERB (Science and Engineering Research Board) and DBT (Department of Biotechnology), Ministry of Science and Technology, Govt. of India is duly acknowledged for providing the funding and other economic assistance (SRG/2020/001306).

Engineering and Wound Healing. Nanomaterials 9 (2), 164-183. doi:10.3390/ nano9020164

Barbash, V. A., Yashchenko, O. V., and Vasylieva, O. A. (2019). Preparation and Properties of Nanocellulose from Miscanthus X Giganteus. J. Nanomater. 2019, 1-9. doi:10.1155/2019/3241968

Barbash, V., Yashchenko, O., and Kedrovska, A. (2017). Preparation and Properties of Nanocellulose from Peracetic Flax Pulp. Jsrr 16 (1), 1-10. doi:10.9734/jsrr/2017/36571

Bardet, R., Reverdy, C., Belgacem, N., Leirset, I., Syverud, K., Bardet, M., et al. (2015). Substitution of Nanoclay in High Gas Barrier Films of Cellulose Nanofibrils with Cellulose Nanocrystals and thermal Treatment. Cellulose 22 (2), 1227-1241. doi:10.1007/s10570-015-0547-9

Bartolozzi, I., Daddi, T., Punta, C., Fiorati, A., and Iraldo, F. (2020). Life Cycle Assessment of Emerging Environmental Technologies in the Early Stage of Development: A Case Study on Nanostructured Materials. J. Ind. Ecol. 24 (1), 101-115. doi:10.1111/jiec.12959

Bastidas, J., Venditti, R., Pawlak, J., Gilbert, R., Zauscher, S., and Kadla, J. (2005). Chemical Force Microscopy of Cellulosic Fibers. Carbohydr. Polym. 62 (4), 369-378. doi:10.1016/j.carbpol.2005.08.058

Beyki, M. H., Bayat, M., and Shemirani, F. (2016). Fabrication of Core-Shell Structured Magnetic Nanocellulose Base Polymeric Ionic Liquid for Effective Biosorption of Congo Red Dye. Bioresour. Technology 218, 326-334. doi:10.1016/j.biortech.2016.06.069

Bhatnagar, A., and Sain, M. (2005). Processing of Cellulose Nanofiber-Reinforced Composites. J. Reinforced Plastics Composites 24, 1259-1268. doi:10.1177/ 0731684405049864

Blair, M. J., and Mabee, W. E. (2021). Techno-economic and Market Analysis of Two Emerging forest Biorefining Technologies. Biofuels, Bioprod. Bioref. 15, 1301-1317. doi:10.1002/bbb.2218

Bodin, A., Concaro, S., Brittberg, M., and Gatenholm, P. (2007). Bacterial Cellulose as a Potential Meniscus Implant. J. Tissue Eng. Regen. Med. 1, 406-408. doi:10.1002/term.51

Bondancia, T. J., De Aguiar, J., Batista, G., Cruz, A. J. G., Marconcini, J. M., Mattoso, L. H. C., et al. (2020). Production of Nanocellulose Using Citric Acid in a Biorefinery Concept: Effect of the Hydrolysis Reaction Time and Techno-Economic Analysis. Ind. Eng. Chem. Res. 59 (25), 11505-11516. doi:10.1021/acs.iecr.0c01359

Börjesson, M., and Westman, G. (2015). Crystalline Nanocellulose - Preparation, Modification, and Properties, Cellulose - Fundamental Aspects and Current Trends, Matheus Poletto and Heitor Luiz Ornaghi Junior. IntechOpen 9, 159-191.

Cao, X., Habibi, Y., Magalhaes, W. L. E., Rojas, O. J., and Lucia, L. A. (2011). Cellulose Nanocrystals-Based Nanocomposites: Fruits of a Novel Biomass Research and Teaching Platform. Curr. Sci., 1172-1176. 
Capron, I. (2018). "Application of Nanocellulose as Pickering Emulsifier," in Application of Nanocellulose as Pickering Emulsifier in Nanocellulose and Sustainability: Production, Properties, Applications, and Case Studies. Editor K. Y. Lee (Boca Raton, FL: CRC Press), 175-196. doi:10.1201/9781351262927-9

Chau, M., Sriskandha, S. E., Pichugin, D., Thérien-Aubin, H., Nykypanchuk, D., Chauve, G., et al. (2015). Ion-mediated Gelation of Aqueous Suspensions of Cellulose Nanocrystals. Biomacromolecules 16, 2455-2462. doi:10.1021/ acs.biomac.5b00701

Chauhan, V. S., and Chakrabarti, S. K. (2012). Use of Nanotechnology for High Performance Cellulosic and Papermaking Products. Cellul. Chem. Technol. 46, 389-400.

Daicho, K., Fujisawa, S., Kobayashi, K., Saito, T., and Ashida, J. (2020). Crosspolarization Dynamics and Conformational Study of Variously Sized Cellulose Crystallites Using Solid-State 13 C NMR. J. Wood Sci. 66 (1), 1-7. doi:10.1186/ s10086-020-01909-9

Damásio, R. A. P., Carvalho, A. G., Gomes, F. J. B., Carneiro, A. d. C. O., Ferreira, J. C., and Colodette, J. L. (2017). Interação de nanocristais de celulose com o adesivo ureia-formaldeído em juntas coladas de Eucalyptus sp. Sci. For. 45 (113), 169-176. doi:10.18671/scifor.v45n113.17

Dasong, D. (2015). Hemp Nanocellulose: Fabrication, Characterisation and Application. Kingston Ln, London: London: Doctoral dissertation, Brunel University London.

Daud, J. B., and Lee, K.-Y. (2017). Surface Modification of Nanocellulose. Handbook of Nanocellulose and Cellulose Nanocomposites 1, 101-122. doi:10.1002/9783527689972.ch3

de Assis, C. A., Houtman, C., Phillips, R., Bilek, E. M., Rojas, O. J., Pal, L., et al. (2017). Conversion Economics of Forest Biomaterials: Risk and Financial Analysis ofCNCManufacturing. Biofuels, Bioprod. Bioref. 11, 682-700. doi:10.1002/bbb.1782

de Figueirêdo, M. C. B., Rosa, M. d. F., Ugaya, C. M. L., Souza Filho, M. d. S. M. d., Silva Braid, A. C. C. d., and Melo, L. F. L. d. (2012). Life Cycle Assessment of Cellulose Nanowhiskers. J. Clean. Prod. 35, 130-139. doi:10.1016/ j.jclepro.2012.05.033

De France, K. J., Hoare, T., and Cranston, E. D. (2017). Review of Hydrogels and Aerogels Containing Nanocellulose. Chem. Mater. 29 (11), 4609-4631. doi:10.1021/acs.chemmater.7b00531

De Olyveira, G. M., Basmaji, P., Xavier Filho, L., Basmaji, P., and Xavier, F. L. (2011). Bacterial Nanocellulose for Medicine Regenerative. J. Nanotechnol Eng. Med. 2, 034001. doi:10.1115/1.4004181

Dhali, K., Ghasemlou, M., Daver, F., Cass, P., and Adhikari, B. (2021). A Review of Nanocellulose as a New Material towards Environmental Sustainability. Sci. Total Environ. 775, 145871. doi:10.1016/j.scitotenv.2021.145871

Dong, C., Zhang, H., Pang, Z., Liu, Y., and Zhang, F. (2013). Sulfonated Modification of Cotton Linter and its Application as Adsorbent for HighEfficiency Removal of Lead(II) in Effluent. Bioresour. Technology 146, 512-518. doi:10.1016/j.biortech.2013.07.108

Du, H., Liu, W., Zhang, M., Si, C., Zhang, X., and Li, B. (2019). Cellulose Nanocrystals and Cellulose Nanofibrils Based Hydrogels for Biomedical Applications. Carbohydr. Polym. 209, 130-144. doi:10.1016/ j.carbpol.2019.01.020

Du, X., Zhang, Z., Liu, W., and Deng, Y. (2017). Nanocellulose-based Conductive Materials and Their Emerging Applications in Energy Devices - a Review. Nano Energy 35, 299-320. doi:10.1016/j.nanoen.2017.04.001

Dufresne, A. (2013). Nanocellulose: a New Ageless Bionanomaterial. Mater. Today 16 (6), 220-227. doi:10.1016/j.mattod.2013.06.004

Edwards, J. V., Fontenot, K. R., Haldane, D., Prevost, N. T., Condon, B. D., and Grimm, C. (2016). Human Neutrophil Elastase Peptide Sensors Conjugated to Cellulosic and Nanocellulosic Materials: Part I, Synthesis and Characterization of Fluorescent Analogs. Cellulose 23, 1283-1295. doi:10.1007/s10570-016-0869-2

Ewulonu, C. M., Liu, X., Wu, M., and Yong, H. (2019). Lignin-Containing Cellulose Nanomaterials: A Promising New Nanomaterial for Numerous Applications. J. Bioresources Bioproducts 4 (1), 3-10. doi:10.21967/jbb.v4i1.186

Ferrer, A., Filpponen, I., Rodríguez, A., Laine, J., and Rojas, O. J. (2012). Valorization of Residual Empty Palm Fruit Bunch Fibers (EPFBF) by Microfluidization: Production of Nanofibrillated Cellulose and EPFBF Nanopaper. Bioresour. Technology 125, 249-255. doi:10.1016/ j.biortech.2012.08.108
Frone, A. N., Panaitescu, D. M., and Donescu, D. (2011). Some Aspects Concerning the Isolation of Cellulose Micro-and Nano-Fibers. UPB Sci. Bull. Ser. B. 73, 133-152.

Gallo Stampino, P., Riva, L., Punta, C., Elegir, G., Bussini, D., and Dotelli, G. (2021). Comparative Life Cycle Assessment of Cellulose Nanofibres Production Routes from virgin and Recycled Raw Materials. Molecules 26 (9), 2558-2620. doi: $10.3390 /$ molecules 26092558

Gan, P. G., Sam, S. T., Abdullah, M. F. B., and Omar, M. F. (2020). Thermal Properties of Nanocellulose-reinforced Composites: A Review. J. Appl. Polym. Sci. 137 (11), 48544. doi:10.1002/app.48544

Gardner, K., and Blackwell, J. (1974). The Hydrogen Bonding in Native Cellulose. Biochim. Biophys. Acta (Bba) - Gen. Subjects 343 (1), 232-237. doi:10.1016/ 0304-4165(74)90256-6

Gbadeyan, O. J., Adali, S., Bright, G., Sithole, B., and Onwubu, S. (2020). Optimization of Milling Procedures for Synthesizing Nano-CaCO3 from Achatina fulica Shell through Mechanochemical Techniques. J. Nanomater. 2020, 1-9. doi:10.1155/2020/4370172

Golmohammadi, H., Morales-Narváez, E., Naghdi, T., and Merkoçi, A. (2017). Nanocellulose in Sensing and Biosensing. Chem. Mater. 29, 5426-5446. doi:10.1021/acs.chemmater.7b01170

Gorgieva, S., and Trček, J. (2019). Bacterial Cellulose: Production, Modification and Perspectives in Biomedical Applications. Nanomaterials 9 (10), 1352. doi:10.3390/nano9101352

Guhados, G., Wan, W., and Hutter, J. L. (2005). Measurement of the Elastic Modulus of Single Bacterial Cellulose Fibers Using Atomic Force Microscopy. Langmuir 21, 6642-6646. doi:10.1021/la0504311

Gupta, G. K., and Shukla, P. (2020). Lignocellulosic Biomass for the Synthesis of Nanocellulose and its Eco-Friendly Advanced Applications. Front. Chem. 8, 601256. doi: $10.3389 /$ fchem. 2020.601256

Habibi, Y., Lucia, L. A., and Rojas, O. J. (2010). Cellulose Nanocrystals: Chemistry, Self-Assembly, and Applications. Chem. Rev. 110 (6), 3479-3500. doi:10.1021/ cr900339w

Hallac, B. B., and Ragauskas, A. J. (2011). Analyzing Cellulose Degree of Polymerization and its Relevancy to Cellulosic Ethanol. Biofuels, Bioprod. Bioref. 5 (2), 215-225. doi:10.1002/bbb.269

Henriksson, M., and Berglund, L. A. (2007). Structure and Properties of Cellulose Nanocomposite Films Containing Melamine Formaldehyde. J. Appl. Polym. Sci. 106, 2817-2824. doi:10.1002/app.26946

Hubbe, M. A., Tayeb, P., Joyce, M., Tyagi, P., Kehoe, M., Dimic-Misic, K., et al. (2017). Rheology of Nanocellulose-Rich Aqueous Suspensions: a Review. BioRes 12 (4), 9556-9661. doi:10.15376/biores.12.4.hubbe

Iwamoto, S., Lee, S.-H., and Endo, T. (2014). Relationship between Aspect Ratio and Suspension Viscosity of wood Cellulose Nanofibers. Polym. J. 46 (1), 73-76. doi:10.1038/pj.2013.64

Iwamoto, S., Nakagaito, A. N., and Yano, H. (2007). Nano-fibrillation of Pulp Fibers for the Processing of Transparent Nanocomposites. Appl. Phys. A. 89, 461-466. doi:10.1007/s00339-007-4175-6

Jiang, F., Dallas, J. L., Ahn, B. K., and Hsieh, Y.-L. (2014). 1D and 2D NMR of Nanocellulose in Aqueous Colloidal Suspensions. Carbohydr. Polym. 110, 360-366. doi:10.1016/j.carbpol.2014.03.043

Jiang, F., Li, T., Li, Y., Zhang, Y., Gong, A., Dai, J., et al. (2018). Wood-based Nanotechnologies toward Sustainability. Adv. Mater. 30 (1), 1703453-1703539. doi:10.1002/adma.201703453

Jiang, G.-p., Zhang, J., Qiao, J.-l., Jiang, Y.-m., Zarrin, H., Chen, Z., et al. (2015). Bacterial nanocellulose/Nafion Composite Membranes for Low Temperature Polymer Electrolyte Fuel Cells. J. Power Sourc. 273, 697-706. doi:10.1016/ j.jpowsour.2014.09.145

Jiang, J., Zhu, Y., and Jiang, F. (2021). Sustainable Isolation of Nanocellulose from Cellulose and Lignocellulosic Feedstocks: Recent Progress and Perspectives. Carbohydr. Polym. 267 (March), 118188. doi:10.1016/j.carbpol.2021.118188

Johar, N., Ahmad, I., and Dufresne, A. (2012). Extraction, Preparation and Characterization of Cellulose Fibres and Nanocrystals from rice Husk. Ind. Crops Prod. 37, 93-99. doi:10.1016/j.indcrop.2011.12.016

Jonasson, S., Bünder, A., Niittylä, T., and Oksman, K. (2020). Isolation and Characterization of Cellulose Nanofibers from aspen wood Using Derivatizing and Non-derivatizing Pretreatments. Cellulose 27 (1), 185-203. doi:10.1007/s10570-019-02754-w 
Jonoobi, M., Oladi, R., Davoudpour, Y., Oksman, K., Dufresne, A., Hamzeh, Y., et al. (2015). Different Preparation Methods and Properties of Nanostructured Cellulose from Various Natural Resources and Residues: a Review. Cellulose 22 (2), 935-969. doi:10.1007/s10570-015-0551-0

Jordan, J. H., Easson, M. W., Dien, B., Thompson, S., and Condon, B. D. (2019). Extraction and Characterization of Nanocellulose Crystals from Cotton Gin Motes and Cotton Gin Waste. Cellulose 26 (10), 5959-5979. doi:10.1007/ s10570-019-02533-7

Jorfi, M., and Foster, E. J. (2014). Recent Advances in Nanocellulose for Biomedical Applications. J. Appl. Polym. Sci. 132 (14), a-n. doi:10.1002/app.41719

Kabir, S. M. F., Sikdar, P. P., Rahman, B. H. M. A., and Ali, B. A. (2018). Cellulosebased Hydrogel Materials: Chemistry, Properties and Their Prospective Applications. Prog. Biomater. 7, 153-174.doi:10.1007/s40204-018-0095-0

Keerati-U-Rai, M., and Corredig, M. (2009). Effect of Dynamic High Pressure Homogenization on the Aggregation State of Soy Protein. J. Agric. Food Chem. 57, 3556-3562. doi:10.1021/jf803562q

Khili, F., Borges, J., Almeida, P. L., Boukherroub, R., and Omrani, A. D. (2019). Extraction of Cellulose Nanocrystals with Structure I and II and Their Applications for Reduction of Graphene Oxide and Nanocomposite Elaboration. Waste Biomass Valor. 10 (7), 1913-1927. doi:10.1007/s12649018-0202-4

Ko, Y., Kim, D., Kim, U.-J., and You, J. (2017). Vacuum-assisted Bilayer PEDOT: PSS/cellulose Nanofiber Composite Film for Self-Standing, Flexible, Conductive Electrodes. Carbohydr. Polym. 173, 383-391. doi:10.1016/ j.carbpol.2017.05.096

Lahiji, R. R., Xu, X., Reifenberger, R., Raman, A., Rudie, A., and Moon, R. J. (2010). Atomic Force Microscopy Characterization of Cellulose Nanocrystals. Langmuir 26 (6), 4480-4488. doi:10.1021/la903111j

Lazarevic, D., and Finnveden, G. (2013). Life Cycle Aspects of Nanomaterials. Available at: http://kth.diva-portal.org/smash/record.jsf?searchId=1\&pid=diva2:650922.

Lee, S.-Y., Chun, S.-J., Kang, I.-A., and Park, J.-Y. (2009). Preparation of Cellulose Nanofibrils by High-Pressure Homogenizer and Cellulose-Based Composite Films. J. Ind. Eng. Chem. 15, 50-55. doi:10.1016/ j.jiec.2008.07.008

Lengowski, E. C., Bonfatti Júnior, E. A., Kumode, M. M. N., Carneiro, M. E., and Satyanarayana, K. G. (2019). "Nanocellulose-reinforced Adhesives for woodbased Panels," in Sustainable Polymer Composites And Nanocomposite, Berlin/ Heidelberg,Germany: Springer, 1001-1025. doi:10.1007/978-3-030-05399$4 \_35 s$

Letchford, L., Jackson, B., WassermanHamad, B., Ye, H., Hamad, W., and Burt, H. (2011). The Use of Nanocrystalline Cellulose for the Binding and Controlled Release of Drugs. Ijn 321, 321. doi:10.2147/ijn.s16749

Li, Q., McGinnis, S., Sydnor, C., Wong, A., and Renneckar, S. (2013). Nanocellulose Life Cycle Assessment. ACS Sustainable Chem. Eng. 1 (8), 919-928. doi:10.1021/sc4000225

Liu, D., Zhong, T., Chang, P. R., Li, K., and Wu, Q. (2010). Starch Composites Reinforced by Bamboo Cellulosic Crystals. Bioresour. Technology 101, 2529-2536. doi:10.1016/j.biortech.2009.11.058

Ludwicka, K., Jedrzejczak-krzepkowska, M., Kubiak, K., Kolodziejczyk, M, Pankiewicz, T, and Bielecki, S (2016). Medical and Cosmetic Applications of Bacterial NanoCellulose, Bacterial Nanocellulose. Editors Gama, M., Dourado, F., and Bielecki, S. (Amsterdam: Elsevier), 145-165. doi:10.1016/B978-0-44463458-0.00009-3

Luo, J., Chang, H., Bakhtiary Davijani, A. A., Liu, H. C., Wang, P.-H., Moon, R. J., et al. (2017). Influence of High Loading of Cellulose Nanocrystals in Polyacrylonitrile Composite Films. Cellulose 24 (4), 1745-1758. doi:10.1007/ s10570-017-1219-8

Mangayil, R., Rajala, S., Pammo, A., Sarlin, E., Luo, J., Santala, V., et al. (2017). Engineering and Characterization of Bacterial Nanocellulose Films as Low Cost and Flexible Sensor Material. ACS Appl. Mater. Inter. 9, 19048-19056. doi:10.1021/acsami.7b04927

Marway, H. (2017). Investigation of Nanocellulose Mechanical Properties and Interactions in Salt and Surfactant Solutions Measured by Atomic Force Microscopy (Doctoral Dissertation).

Mishra, R. K., Sabu, A., and Tiwari, S. K. (2018). Materials Chemistry and the Futurist Eco-Friendly Applications of Nanocellulose: Status and prospect. J. Saudi Chem. Soc. 22, 949-978. doi:10.1016/j.jscs.2018.02.005
Mohaiyiddin, M. S., Lin, O. H., Owi, W. T., Chan, C. H., Chia, C. H., Zakaria, S., et al. (2016). Characterization of Nanocellulose Recovery from Elaeis Guineensis Frond for Sustainable Development. Clean. Techn Environ. Pol. 18 (8), 2503-2512. doi:10.1007/s10098-016-1191-2

Mohammed, N., Grishkewich, N., and Tam, K. C. (2018). Cellulose Nanomaterials: Promising Sustainable Nanomaterials for Application in Water/wastewater Treatment Processes. Environmental Science: Nano 5, 623-658. doi:10.1039/ C7EN01029J

NairJYDengRagauskas, S. S. Z. Y. A. J. (2014). High Performance green Barriers Based on Nanocelluloses Sustain. Chem. Process. 2, 1-7. doi:10.1186/s40508014-0023-0

Nakagaito, A. N., and Yano, H. (2005). Novel High-Strength Biocomposites Based on Microfibrillated Cellulose Having Nano-Order-Unit Web-like Network Structure. Appl. Phys. A. 80, 155-159. doi:10.1007/s00339-003-2225-2

Nasir, M., Gupta, A., Hossen Beg, M. D., Chua, G. K., and Asim, M. (2014). Laccase Application in Medium Density Fibreboard to Prepare a Bio-Composite. RSC Adv. 4, 11520-11527. doi:10.1039/c3ra40593a

Negi, H., Agrawal, R., Verma, A., and Goel, R. (2019). "Municipal Solid Waste to Bioenergy: Current Status, Opportunities, and Challenges in Indian Context," in New and Future Developments in Microbial Biotechnology and Bioengineering. Editors J.S. Singh and D.P. Singh (Amsterdam, Netherlands: Elsevier), 191-203. doi:10.1016/b978-0-444-64191-5.00014-6

Nguyen, L. H., Naficy, S., Chandrawati, R., and Dehghani, F. (2019). Nanocellulose for Sensing Applications. Adv. Mater. Inter. 6, 1900424. doi:10.1002/ admi.201900424

Nirmal, N., Pillay, M. N., Mariola, M., Petruccione, F., and van Zyl, W. E. (2020). Formation of Dialysis-free Kombucha-Based Bacterial Nanocellulose Embedded in a Polypyrrole/PVA Composite for Bulk Conductivity Measurements. RSC Adv. 10 (46), 27585-27597. doi:10.1039/d0ra04649c

Ottesen, V., and Syverud, K. (2021). Swelling of Individual Cellulose Nanofibrils in Water, Role of Crystallinity: an AFM Study. Cellulose 28, 19-29. doi:10.1007/ s10570-020-03517-8

Pääkkö, M., Ankerfors, M., Kosonen, H., Nykänen, A., Ahola, S., Österberg, M., et al. (2007). Enzymatic Hydrolysis Combined with Mechanical Shearing and High-Pressure Homogenization for Nanoscale Cellulose Fibrils and strong Gels. Biomacromolecules 8, 1934-1941. doi:10.1021/bm061215p

Parvej, M. S., Wang, X., and Jiang, L. (2020). AFM Based Nanomechanical Characterization of Cellulose Nanofibril. J. Compos. Mater. 54 (28), 4487-4493. doi:10.1177/0021998320933955

Petersen, N., and Gatenholm, P. (2011). Bacterial Cellulose-Based Materials and Medical Devices: Current State and Perspectives. Appl. Microbiol. Biotechnol. 91, 1277-1286. doi:10.1007/s00253-011-3432-y

Phanthong, P., Reubroycharoen, P., Hao, X., Xu, G., Abudula, A., and Guan, G. (2018). Nanocellulose: Extraction and Application. Carbon Resour. Convers. 1 (1), 32-43. doi:10.1016/j.crcon.2018.05.004

Piccinno, F., Hischier, R., Seeger, S., and Som, C. (2015). Life Cycle Assessment of a New Technology to Extract, Functionalize and orient Cellulose Nanofibers from Food Waste. ACS Sustainable Chem. Eng. 3 (6), 1047-1055. doi:10.1021/ acssuschemeng. 5 b00209

Piccinno, F., Hischier, R., Seeger, S., and Som, C. (2018). Predicting the Environmental Impact of a Future Nanocellulose Production at Industrial Scale: Application of the Life Cycle Assessment Scale-Up Framework. J. Clean. Prod. 174, 283-295. doi:10.1016/j.jclepro.2017.10.226

Plackett, D., Letchford, K., Jackson, J., and Burt, H. (2014). A Review of Nanocellulose as a Novel Vehicle for Drug Delivery. Nord Pulp Pap. Res. J. 29, 105-118. doi:10.3183/npprj-2014-29-01-p105-118

Pottathara, Y. B., Bobnar, V., Gorgieva, S., Grohens, Y., Finšgar, M., Thomas, S., et al. (2016). Mechanically strong, Flexible and Thermally Stable Graphene Oxide/nanocellulosic Films with Enhanced Dielectric Properties. RSC Adv. 6, 49138-49149.

Raghavendra, G. M., Varaprasad, K., and Jayaramudu, T. (2015). Chapter 2. Biomaterials Design, Development and Biomedical Applications. Amsterdam: Elsevier.

Razaq, A., Nyström, G., Strømme, M., Mihranyan, A., and Nyholm, L. (2011). High-capacity Conductive Nanocellulose Paper Sheets for Electrochemically Controlled Extraction of DNA Oligomers. PLoS One 6, e29243. doi:10.1371/ journal.pone.0029243 
Rebouillat, S., and Pla, F. (2013). State of the Art Manufacturing and Engineering of Nanocellulose: A Review of Available Data and Industrial Applications. Jbnb 04 (02), 165-188. doi:10.4236/jbnb.2013.42022

Reshmy, R., Philip, E., Paul, S. A., Madhavan, A., Sindhu, R., Binod, P., et al. (2020). Nanocellulose-based Products for Sustainable Applications-Recent Trends and Possibilities. Rev. Environ. Sci. Biotechnol. 19 (4), 779-806. doi:10.1007/s11157020-09551-z

Risti, T., Zemljič, L., Novak Babič, M., Kralj Kuncic, M., Sonjak, S., Gundecimerman, N., et al. (2011). "Antimicrobial Efficiency of Functionalised Cellulose Fibers as Potential Medical Textiles," in Science Aganist Microbial Pathogens: Communicating Current Research and Technology Advances (Badajoz: Formatex Research Center), 37-51.

Roman, M., and Winter, W. T. (2004). Effect of Sulfate Groups from Sulfuric Acid Hydrolysis on the thermal Degradation Behavior of Bacterial Cellulose. Biomacromolecules 5, 1671-1677. doi:10.1021/bm034519+

Salieri, B., Turner, D. A., Nowack, B., and Hischier, R. (20182017). Life Cycle Assessment of Manufactured Nanomaterials: Where Are We? NanoImpact 10, 108-120. doi:10.1016/j.impact.2017.12.003

Satlewal, A., Agrawal, R., Bhagia, S., Das, P., and Ragauskas, A. J. (2018a). Rice Straw as a Feedstock for Biofuels: Availability, Recalcitrance, and Chemical Properties. Biofuels, Bioprod. Bioref. 12 (1), 83-107. doi:10.1002/bbb. 1818

Satlewal, A., Agrawal, R., Bhagia, S., Sangoro, J., and Ragauskas, A. J. (2018b). Natural Deep Eutectic Solvents for Lignocellulosic Biomass Pretreatment: Recent Developments, Challenges and Novel Opportunities. Biotechnol. Adv. 36 (8), 2032-2050. doi:10.1016/j.biotechadv.2018.08.009

Schlesinger, M., Hamad, W. Y., and Maclachlan, M. J. (2015). Optically Tunable Chiral Nematic Mesoporous Cellulose Films. Soft Matter 11, 4686-4694. doi: $10.1039 / \mathrm{c} 5 \mathrm{sm} 00745 \mathrm{c}$

Segal, L., Creely, J. J., Martin, A. E., Jr, and Conrad, C. M. (1959). An Empirical Method for Estimating the Degree of Crystallinity of Native Cellulose Using the X-ray Diffractometer. Textile Res. J. 29 (10), 786-794. doi:10.1177/ 004051755902901003

Shafeiei-Sabet, S., Hamad, W. Y., and Hatzikiriakos, S. G. (2013). Influence of Degree of Sulfation on the Rheology of Cellulose Nanocrystal Suspensions. Rheologica Acta 52 (8-9), 741-751. doi:10.1007/s00397-013-0722-6

ShakYee, K. P. Y., Pang, Y. L., and Mah, S. K. (2018). Nanocellulose: Recent Advances and its Prospects in Environmental Remediation. Beilstein J. Nanotechnol. 9 (1), 2479-2498. doi:10.3762/bjnano.9.232

Shen, R., Xue, S., Xu, Y., Liu, Q., Feng, Z., Ren, H., et al. (2020). Research Progress and Development Demand of Nanocellulose Reinforced Polymer Composites. Polymers (Basel) 12, 1-19. doi:10.3390/polym12092113

Shi, Z., Phillips, G. O., and Yang, G. (2013). Nanocellulose Electroconductive Composites. Nanoscale 5, 3194-3201. doi:10.1039/c3nr00408b

Silva, F. A. G. S., Dourado, F., Gama, M., and Poças, F. (2020). Nanocellulose BioBased Composites for Food Packaging. Nanomaterials 10 (10), 2041. doi:10.3390/nano10102041

Siró, I., and Plackett, D. (2010). Microfibrillated Cellulose and New Nanocomposite Materials: a Review. Cellulose 17, 459-494. doi:10.1007/ s10570-010-9405-y

Sofla, M. R. K., Brown, R. J., Tsuzuki, T., and Rainey, T. J. (2016). A Comparison of Cellulose Nanocrystals and Cellulose Nanofibres Extracted from Bagasse Using Acid and ball Milling Methods. Adv. Nat. Sci. Nanosci. Nanotechnol. 7 (3), 035004. doi:10.1088/2043-6262/7/3/035004

Squinca, P., Bilatto, S., Badino, A. C., and Farinas, C. S. (2020). Nanocellulose Production in Future Biorefineries: An Integrated Approach Using TailorMade Enzymes. ACS Sustainable Chem. Eng. 8 (5), 2277-2286. doi:10.1021/ acssuschemeng.9b06790

Stoeckel, F., Konnerth, J., and Gindl-Altmutter, W. (2013). Mechanical Properties of Adhesives for Bonding wood-A Review. Int. J. Adhes. Adhesives 45, 32-41. doi:10.1016/j.ijadhadh.2013.03.013

Su, Y., Zhao, Y., Zhang, H., Feng, X., Shi, L., and Fang, J. (2017). Polydopamine Functionalized Transparent Conductive Cellulose Nanopaper with Long-Term Durability. J. Mater. Chem. C 5 (3), 573-581. doi:10.1039/c6tc04928a

Sundarraj, A. A., and Ranganathan, T. V. (2018). A Review on Cellulose and its Utilization from Agro-Industrial Waste. Drug Invent. Today 10 (1), 89-94.
Suryanegara, L., Nakagaito, A. N., and Yano, H. (2010). Thermo-mechanical Properties of Microfibrillated Cellulose-Reinforced Partially Crystallized PLA Composites. Cellulose 17, 771-778. doi:10.1007/s10570-010-9419-5

Thakur, V. K. (2014). Nanocellulose Polymer Nanocomposites: Fundamentals and Applications. Hoboken, New Jersey, United States: Wiley.

Thomas, B., Raj, M. C., B, A. K., H, R. M., Joy, J., Moores, A., et al. (2018). Nanocellulose, a Versatile green Platform: from Biosources to Materials and Their Applications. Chem. Rev. 118 (24), 11575-11625. doi:10.1021/ acs.chemrev.7b00627

Tingaut, P., Zimmermann, T., and Sèbe, G. (2012). Cellulose Nanocrystals and Microfibrillated Cellulose as Building Blocks for the Design of Hierarchical Functional Materials. J. Mater. Chem. 22 (38), 20105. doi:10.1039/c2jm32956e

Trache, D., Tarchoun, A. F., Derradji, M., Hamidon, T. S., Masruchin, N., Brosse, N., et al. (2020). Nanocellulose: From Fundamentals to Advanced ApplicationsFrontiers in Chemistry. Front. Chem. 8 (Issue May), 1-33. doi: $10.3389 /$ fchem. 2020.00392

Trifol, J., Plackett, D., Sillard, C., Szabo, P., Bras, J., and Daugaard, A. E. (2016). Hybrid Poly(lactic Acid)/nanocellulose/nanoclay Composites with Synergistically Enhanced Barrier Properties and Improved Thermomechanical Resistance. Polym. Int. 65, 988-995. doi:10.1002/pi.5154

Ugrin, M., Dinic, J., Jeremic, S., Dragicevic, S., Banovic Djeri, B., and Nikolic, A. (2021). Bacterial Nanocellulose as a Scaffold for In Vitro Cell Migration Assay. Nanomaterials 11, 2322. doi:10.3390/nano11092322

Ureña-Benavides, E. E., Ao, G., Davis, V. A., and Kitchens, C. L. (2011). Rheology and Phase Behavior of Lyotropic Cellulose Nanocrystal Suspensions. Macromolecules 44 (22), 8990-8998. doi:10.1021/ma201649f

Usov, I., Nyström, G., Adamcik, J., Handschin, S., Schütz, C., Fall, A., et al. (2015). Understanding Nanocellulose Chirality and Structure-Properties Relationship at the Single Fibril Level. Nat. Commun. 6 (1), 7564-7611. doi:10.1038/ ncomms 8564

Veigel, S., Rathke, J., Weigl, M., and Gindl-Altmutter, W. (2012). Particle Board and Oriented Strand Board Prepared with Nanocellulose-Reinforced Adhesive. J. Nanomater. 2012, 1-8. doi:10.1155/2012/158503

Verma, A., Ansari, M. W., Anwar, M. S., Agrawal, R., and Agrawal, S. (2014). Alkaline Protease from Thermoactinomyces Sp. RS1 Mitigates Industrial Pollution. Protoplasma 251, 711-718. doi:10.1007/s00709-013-0559-y

Ververis, C., Georghiou, K., Christodoulakis, N., Santas, P., and Santas, R. (2004). Fiber Dimensions, Lignin and Cellulose Content of Various Plant Materials and Their Suitability for Paper Production. Ind. crops Prod. 19 (3), 245-254. doi:10.1016/j.indcrop.2003.10.006

Vilela, C., Morais, J. D., Silva, A. C. Q., Muñoz-Gil, D., Figueiredo, F. M. L., Silvestre, A. J. D., et al. (2020). Flexible Nanocellulose/Lignosulfonates IonConducting Separators for Polymer Electrolyte Fuel Cells. Nanomaterials 10 (9), 1713. doi:10.3390/nano10091713

Wang, B., and Sain, M. (2007). Dispersion of Soybean Stock-Based Nanofiber in a Plastic Matrix. Polym. Int. 56, 538-546. doi:10.1002/pi.2167

Wang, Q., Yao, Q., Liu, J., Sun, J., Zhu, Q., and Chen, H. (2019). Processing Nanocellulose to Bulk Materials: a Review. Cellulose 26, 7585-7617. doi:10.1007/s10570-019-02642-3

Wang, T., and Drzal, L. T. (2012). Cellulose-Nanofiber-Reinforced Poly(lactic Acid) Composites Prepared by a Water-Based Approach. ACS Appl. Mater. Inter. 4 (10), 5079-5085. doi:10.1021/am301438g

Way, A. E., Hsu, L., Shanmuganathan, K., Weder, C., and Rowan, S. J. (2012). pHResponsive Cellulose Nanocrystal Gels and Nanocomposites. ACS Macro Lett. 1, 1001-1006. doi:10.1021/mz3003006

$\mathrm{Xu}, \mathrm{Y}$., and $\mathrm{Gu}, \mathrm{J} .(2020)$. Investigation on the Interaction Mechanism between Nanocellulose and Adhesion RH. Surf Interf. Anal 52 (8), 518-529. doi:10.1002/ sia.6772

Yan, X., Zihao, M., and Huining, X. (2017). Nanocellulose as Sustainable Biomass Material: Structure, Properties, Present Status and Future Prospects in Biomedical Applications. Nanoscale 9, 14758-14781.

Yang, X., Han, F., Xu, C., Jiang, S., Huang, L., Liu, L., et al. (2017). Effects of Preparation Methods on the Morphology and Properties of Nanocellulose (NC) Extracted from Corn Husk. Ind. Crops Prod. 109, 241-247. doi:10.1016/ j.indcrop.2017.08.032

Yu, X., Tong, S., Ge, M., Wu, L., Zuo, J., Cao, C., et al. (2013). Adsorption of Heavy Metal Ions from Aqueous Solution by Carboxylated Cellulose Nanocrystals. J. Environ. Sci. 25, 933-943. doi:10.1016/s1001-0742(12)60145-4 
Yue, Y., Wang, X., Han, J., Yu, L., Chen, J., Wu, Q., et al. (2019). Effects of Nanocellulose on Sodium Alginate/polyacrylamide Hydrogel: Mechanical Properties and Adsorption-Desorption Capacities. Carbohydr. Polym. 206, 289-301. doi:10.1016/j.carbpol.2018.10.105

Zargar, S., Jiang, J., Jiang, F., and Tu, Q. (2021). Isolation of Lignin-containing Cellulose Nanocrystals: Life-cycle Environmental Impacts and Opportunities for Improvement. Biofuels, Bioprod. Bioref., 1-13. doi:10.1002/bbb.2261

Zhang, L., Tsuzuki, T., and Wang, X. (2015). Preparation of Cellulose Nanofiber from Softwood Pulp by ball Milling. Cellulose 22, 1729-1741. doi:10.1007/ s10570-015-0582-6

Zimmermann, T., Bordeanu, N., and Strub, E. (2010). Properties of Nanofibrillated Cellulose from Different Raw Materials and its Reinforcement Potential. Carbohydr. Polym. 79 (4), 1086-1093. doi:10.1016/j.carbpol.2009.10.045

Zuluaga, R., Putaux, J.-L., Restrepo, A., Mondragon, I., and Gañán, P. (2007). Cellulose Microfibrils from Banana Farming Residues: Isolation and Characterization. Cellulose 14, 585-592. doi:10.1007/s10570-007-9118-z
Conflict of Interest: The authors declare that the research was conducted in the absence of any commercial or financial relationships that could be construed as a potential conflict of interest.

Publisher's Note: All claims expressed in this article are solely those of the authors and do not necessarily represent those of their affiliated organizations, or those of the publisher, the editors and the reviewers. Any product that may be evaluated in this article, or claim that may be made by its manufacturer, is not guaranteed or endorsed by the publisher.

Copyright $\odot 2021$ Kaur, Sharma, Munagala, Rajkhowa, Aallardyce, Shastri and Agrawal. This is an open-access article distributed under the terms of the Creative Commons Attribution License (CC BY). The use, distribution or reproduction in other forums is permitted, provided the original author(s) and the copyright owner(s) are credited and that the original publication in this journal is cited, in accordance with accepted academic practice. No use, distribution or reproduction is permitted which does not comply with these terms. 